
\title{
Insights in Perovskite Solar Cell Fabrication: Unraveling the Hidden Challenges of Each Layer
}

\author{
Verena Stockhausen, Isabel Mesquita, Luísa Andrade, and Adélio Mendes ()
}

\begin{abstract}
Perovskite solar cells (PSC) are undoubtedly the most active research area in photovoltaics at this moment. Actually, since 2009 this emerging technology passed from $3.8 \%$ to the present $>22 \%$ of energy conversion efficiency. Along with that, a huge amount of sometimes contradicting and incomplete information about how to prepare and characterize PSC is provided, which makes it difficult to not get lost. This paper is mainly directed toward newcomers in this area, with the goal to give orientation for PSC fabrication protocols that are quickly implementable and that lead to reliable and acceptable efficiencies. Therefore, a step-by-step analysis of each layer is provided and, within this scope, several fabrication techniques are compared in terms of efficiency optimization. Furthermore, a new and versatile alternative to laser-assisted scribing for substrate patterning is presented. Electrochemical characterization of dummy cells as an easy and versatile tool for isolated layer characterization is demonstrated for $\mathrm{TiO}_{2}$ blocking layers. After optimization of each layer, PSC with an average efficiency of $(14.8 \pm 1.0) \%$ was obtained.
\end{abstract}

Index Terms-Blocking layer, fabrication details, performance, perovskite solar cells.

\section{INTRODUCTION}

$\mathbf{G}$ LOBAL energy consumption is projected to raise by $48 \%$ from 2012 to 2040 [1], which makes the intensification of renewable energy implementation unavoidable. Among them, solar energy production has been the fastest growing sector with the biggest share in newly created jobs in the past few

Manuscript received December 22, 2017; revised April 4, 2018; accepted April 6, 2018. This work was supported in part by the European Union's Horizon 2020 Programme, through a FET Open research and innovation action under Grant 687008, in part by the Project POCI-01-0145-FEDER-006939 (LEPABE - Laboratory for Process Engineering, Environment, Biotechnology and Energy - UID/EQU/00511/2013), funded by the European Regional Development Fund, through COMPETE2020 - Programa Operacional Competitividade e Internacionalização (POCI) and by nationals funds through FCT (Fundação para a Ciência e a Tecnologia), and in part by NORTE-01-0145-FEDER-000005 - LEPABE-2-ECO-INNOVATION, supported by North Portugal Regional Operational Programme (Norte 2020), under the Portugal 2020 Partnership Agreement, through the European Regional Development Fund. The work of V. Stockhausen was supported by the European Commission through the Seventh Framework Program, the Specific Program "Ideas" of the European Research Council for research and technological development as part of an Advanced Grant under Grant 321315 (BI-DSC). The work of I. Mesquita was supported by the FCT for her Ph.D. fellow (ref.: PD/PB/105985/2014). The work of L. Andrade was supported by the FCT (IF/01331/2015). (Corresponding author: Adélio Mendes.)

The authors are with the Faculdade de Engenharia, Universidade do Porto, Porto 4200-465, Portugal (e-mail: verena@fe.up.pt; mesquita@fe.up.pt; landrade@fe.up.pt; mendes@fe.up.pt).

Color versions of one or more of the figures in this paper are available online at http://ieeexplore.ieee.org.

Digital Object Identifier 10.1109/JPHOTOV.2018.2826055 years [2], [3]. Besides the mature silicon technology, advanced copper indium gallium selenide and CdTe solar cells lately entering the market, perovskite solar cells (PSC) have been earning a lot of attention due to their striking performance evolution since 2012 [4]. Since then, PSC efficiencies have been ramping up quickly, reaching certified record efficiencies of $22.7 \%$ for laboratory devices [5]; more recently, in February 2018, Grätzel reported 23.3\% at ABXPV conference, Rennes [6]. Despite the fast progress in fabricating PSC with high efficiency, stability has been a limiting factor so far. Thus, attempting to address efficiency and stability, a huge variety of formulations and cell architectures has been published. It includes planar devices using an inverted $\mathrm{p}-\mathrm{i}-\mathrm{n}$ architecture and PSC employing a mesoporous structure that can either actively participate in the electron transfer (active mesoporous layer) or merely serve as scaffold structure (passive mesoporous layer). Within perovskites, chemical engineering has originated a huge quantity of mixed structures, employing mixed cations and anions. Many laboratories have been deciding to direct research efforts toward this "shooting star," but not all of them were capable to reproduce the outstanding results published in the literature. Even without regarding long-term stability, efficiencies often remain below expectations because usually, crucial technical details remain barely explained or even unmentioned in research articles. Thus, little fabrication errors within each layer of the PSC will sum up and lead to an overall efficiency drop. Therefore, merely considering efficiencies of entire devices makes reproduction of published results a hard task.

In this paper, a step-by-step analysis of the technical problems of each layer is provided and a possible impact of their modification on the cell performance will be assessed. In the end, the characterization of the entire device is discussed. As record efficiency PSC's generally possess a cell architecture with an active mesoporous layer [7], focus will lie on this PSC structure. For a deeper discussion about alternative cell architectures, interested readers are referred to the informative review of Salim et al. [8], Mesquita et al. [9] or the recent book written by Park et al. [10].

\section{Materials AND MethodS}

Fig. 1 shows a schematic representation of the PSC. On top of a transparent conductive oxide (TCO) substrate that was scribed in order to impede shortcircuiting (grey line), a dense $\mathrm{TiO}_{2}$ layer is deposited, followed by a mesoporous layer. The adjacent perovskite layer partially infiltrates into the mesoporous structure and forms a capping layer. It is followed by a layer of hole 

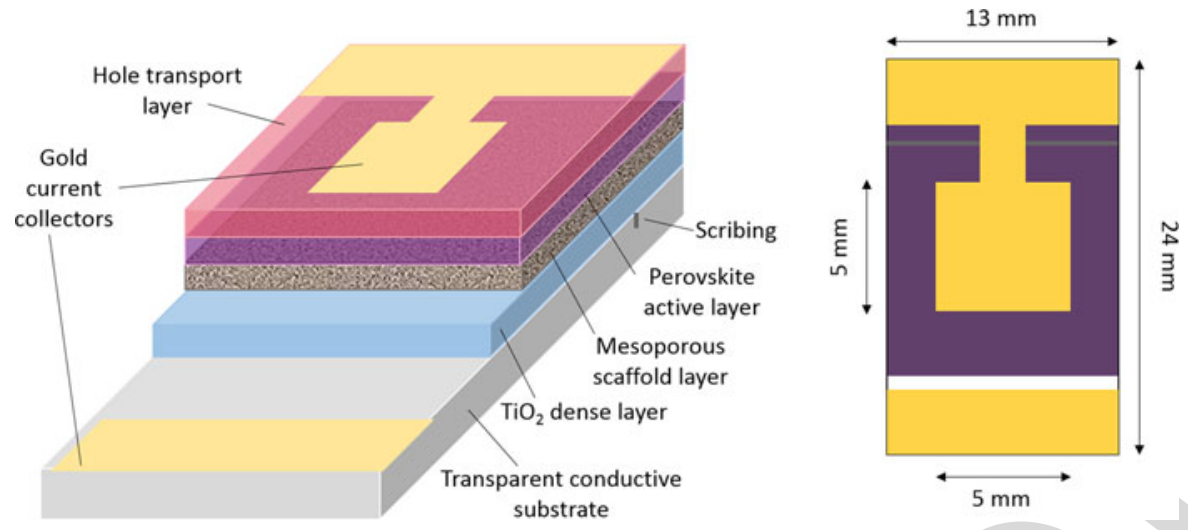

Fig. 1. Schematic representation of a mesoscopic PSC in cross section (left) and top view (right).

transport material (HTM); finally, a nanometric metallic layer serves as a current collector.

In the following, layer fabrication details and, when applicable, alternative fabrication methods are presented. Furthermore, it will be discussed what equipment is required for cell fabrication and which equipment acquisition can be postponed, thanks to alternative fabrication protocols.

\section{A. Substrate Preparation}

Fluoride-doped tin oxide (FTO) substrates $(2.2 \mathrm{~mm}$ thickness, TEC7, Solaronix) were patterned via VersaLaser (VLS 2.30, Universal Laser Systems, USA) to create two separate charge collection areas on the FTO substrate-method (A). As an alternative to laser scribing, which requires the availability of such an equipment, an electrochemical reductive treatment can be performed to remove selectively the conductive layermethod (B). Keep into consideration that the chemicals used for that purpose are highly corrosive, which requires adequate protection and care. In order to do so, the substrate area for TCO removal was delimited by Kapton tape and exposed to a $3 \mathrm{M}$ $\mathrm{HCl}$ solution. A constant potential of $-2.4 \mathrm{~V}$ was applied until cathodic current decrease started to flatten. Meanwhile, the tin oxide of the FTO turned grey and started to peel off; samples were removed from the solution and rinsed with water. With a cotton swab dipped in a diluted nitric acid solution $(0.5 \mathrm{M})$, remaining tin residues were cleaned off. Then, Kapton tape was removed and samples were abundantly rinsed with water.

In a next step, samples were mechanically cleaned, using a toothbrush and a $10 \%$ Hellmanex III (Hellma GmbH, Germany) solution. Subsequently, substrates were abundantly rinsed with water and sonicated in ethanolic $\mathrm{KOH}$ solution for $5 \mathrm{~min}$. The substrates were again abundantly rinsed with water and sonicated in water for $5 \mathrm{~min}$, before being rinsed with acetone and dried in nitrogen flux. Prior to blocking layer deposition, substrates were additionally cleaned for 20 min by an ozone cleaner (UVO-Cleaner, Jelight Company Inc., USA). Alternatively to an ozone cleaner, plasma treatment can be applied [11], among other efficient methods.

\section{B. Electron Blocking $(B L)$ and Mesoporous Layer Preparation}

$\mathrm{TiO}_{2}$ blocking layer was deposited by two different methods. Method (A) was done by spincoating of a commercial solution
(Ti-Nanoxide BL/SC, Solaronix, Switzerland) $(5000 \mathrm{r} / \mathrm{min}, 30 \mathrm{~s}$, $2000(\mathrm{r} / \mathrm{min}) / \mathrm{s})$. Before film deposition, the area of photoanode contact was protected by adhesive strip (Scotch Magic Tape, $3 \mathrm{M}$ ) and the films were subsequently calcined at $550{ }^{\circ} \mathrm{C}$ for $1 \mathrm{~h}$, under application of a stepwise temperature increase of $100{ }^{\circ} \mathrm{C}$ each $10 \mathrm{~min}$. Method (B) employed spray pyrolysis of a precursor solution containing $0.56 \mathrm{M}$ acetylacetone (Sigma-Aldrich, 99.6\%) and 0.18 M titanium diisopropoxide bis(acetylacetonate) (Sigma-Aldrich, $75 \mathrm{wt} . \%$ in isopropanol) in $7 \mathrm{~mL}$ isopropanol (Sigma-Aldrich, anhydrous, 99.5\%) that was sufficient for 64 samples. Here, substrates were preheated at $450{ }^{\circ} \mathrm{C}$ and the photoanode area was protected with a glass stripe before applying the spray via an atomizer, using either air or oxygen as carrier gas. Afterward, samples were left for $45 \mathrm{~min}$ more at that temperature. For application of mesoporous $\mathrm{TiO}_{2}$, a commercial paste (generally 30-NR-D, Dyesol, Australia, unless otherwise stated) was diluted in pure ethanol $(1: 6 \mathrm{w} / \mathrm{w})$ and applied on the substrates via spincoating $(5000 \mathrm{r} / \mathrm{min}, 10 \mathrm{~s}, 2000$ $(\mathrm{r} / \mathrm{min}) / \mathrm{s})$. Prior to deposition, photoanode contact had been protected by adhesive stripes. Samples were then immediately transferred on a heat plate at $100{ }^{\circ} \mathrm{C}$ for predrying before being calcined in a furnace at $500{ }^{\circ} \mathrm{C}$ for $30 \mathrm{~min}$. Subsequently, samples were transferred to oxygen-free and dry conditions (glove box) before allowing to cool below $100{ }^{\circ} \mathrm{C}$.

\section{Perovskite Active Layer Preparation}

The perovskite precursor solution was prepared according to the following conditions published by Saliba et al. [12]: 1.1 M $\mathrm{PbI}_{2}$ (Sigma-Aldrich, 99.999\% trace metal basis), $0.2 \mathrm{M} \mathrm{PbBr}_{2}$ (Sigma-Aldrich, 99.999\% trace metal basis), $0.2 \mathrm{M}$ methylammonium bromide (Dyesol), and $1.0 \mathrm{M}$ formamidinium iodide (Dyesol) were dissolved in $1 \mathrm{~mL}$ of a DMF/DMSO mixture ( $8: 2$ v/v, both Sigma-Aldrich, 99.8 and $\geq 99.9 \%$, respectively). From this solution, $0.95 \mathrm{~mL}$ were added to $0.05 \mathrm{~mL}$ of a $1.5 \mathrm{M} \mathrm{CsI}$ stock solution in DMSO (Sigma-Aldrich, 99.999\% trace metals basis). This final solution was deposited on the substrates by applying a two-step spincoating program (step 1: $1000 \mathrm{r} / \mathrm{min}$, $10 \mathrm{~s}, 200(\mathrm{r} / \mathrm{min}) / \mathrm{s}$, step 2: $6000 \mathrm{r} / \mathrm{min}, 30 \mathrm{~s}, 2000(\mathrm{r} / \mathrm{min}) / \mathrm{s})$. After $25 \mathrm{~s}, 100 \mu \mathrm{L}$ chlorobenzene was poured onto the spinning substrate, a procedure which is known as antisolvent technique. Careful adjustment of dripping speed and tip-to-sample distance had to be trained to fabricate samples in a reproducible manner. 
Samples appeared brown immediately after spincoating and were subsequently sintered at $100{ }^{\circ} \mathrm{C}$ for $40 \mathrm{~min}$ before being allowed to cool down. After each deposition, the interior of the spin coater was cleaned with a cloth to remove the condensed chemicals.

\section{Hole Conducting Layer and Current Collector}

Two different hole conductors were tested: method (A) spiro-OMeTAD solution contained $75 \mathrm{mM}$ spiroOMeTAD (Chemborun, 99.7\% sublimed grade), $0.24 \mathrm{M}$ 4-tert-butylpyridine (Sigma-Aldrich, $96 \%$ ), $41 \mathrm{mM}$ lithium bistrifluoromethanesulfonimidate (Li-TFSI, Acros Organics) that was obtained from a $1.8 \mathrm{M}$ stock solution in acetonitrile (Sigma-Aldrich, $99.999 \%$ electronic grade), and $27 \mathrm{mM} \mathrm{FK}$ 209 Co(III) TFSI salt (Dyesol) that was obtained from a 0.27 $\mathrm{M}$ stock solution in acetonitrile. The solution was deposited via spincoating (4000 r/min, $20 \mathrm{~s}, 2000$ (r/min)/s). Method (B): P3HT solution was fabricated from $15 \mathrm{mg} / \mathrm{mL}$ P3HT (Chemborun China), $23 \mathrm{mM}$ 4-tert-butylpyridine, and $0.7 \mathrm{mM} \mathrm{Li}$ TFSI. It was deposited by spincoating (3000 r/min, $30 \mathrm{~s}, 2000$ $(\mathrm{r} / \mathrm{min}) / \mathrm{s})$. Afterward, photoanode contacts covered with perovskite and hole conductor were mechanically cleaned with a scalpel and cotton swabs dipped in acetonitrile. Finally, a 60-nm-thick gold layer as current collector was applied through a stainless steel mask by two different methods: 1) by thermal evaporation on a VaporStation 4 (Oxford Vacuum Science, U.K.), applying a deposition rate of $0.01 \mathrm{~nm} / \mathrm{s}$ for the first $4 \mathrm{~nm}$, followed by $0.1 \mathrm{~nm} / \mathrm{s}$ for the remaining thickness; and 2) by sputtering using a Leica EM ACE200 (Leica Microsystems, Germany) and applying a current of $60 \mathrm{~mA}$ and a deposition duration of $360 \mathrm{~s}$. A mask of adhesive black tape with an active area of $0.2 \mathrm{~cm}^{2}$ was applied on the glass side of the cell prior to photoelectrochemical characterization.

\section{E. Dummy Cell Preparation}

The preparation was analogous to PSC, however, applying merely blocking layer, hole transport layer, and gold layer by thermal evaporation.

\section{F. Characterization}

For photoelectrochemical characterization, a 150-W solar simulator Oriel class A solar simulator, (Newport, USA) using a 1.5 air mass filter (Newport, USA) was employed. The effective irradiation intensity was measured with a single crystal $\mathrm{Si}$ photodiode (Newport, USA). $I-V$ curves were recorded with a potentiostat (Zennium, Zahner-Elektrik $\mathrm{GmbH}$, Germany) at a scan rate of $10 \mathrm{mV} / \mathrm{s}$, sweeping from open-circuit to short-circuit potential (backward scan). Before each measurement, the opencircuit potential $V_{\text {OC }}$ was allowed to stabilize under irradiation, which generally took less than a minute. Care was taken that starting potentials were chosen to be not more than $20 \mathrm{mV}$ superior to $V_{\mathrm{OC}}$ in order to protect the cell [13]. At least three cells of each type were tested for averaged efficiencies. SEM images were recorded with a Quanta 400 FEG (FEI, USA) at the CEMUP materials analysis center of the University of Porto.

\section{RESULTS AND DISCUSSION}

FTO on glass is usually employed as transparent conductive substrate, due to its stability toward elevated temperatures. Several sheet resistances are available on the market and generally FTO with a sheet resistance of $7-10 \Omega / \mathrm{sq}$ is chosen, as it is a good compromise in terms of conductivity versus transparency. Thorough substrate cleaning is an essential step and often underrated; however, it plays a pivotal role as the perovskite solar cell is constituted by several layers that are all within the nanometer scale and any contamination of the substrate will thus lead to film defects that lower overall cell efficiency. The scribing of the substrate locally removes the TCO layer and impedes the electric short circuit through the substrate of the photoanode and the cathode. It is often obtained by laser ablation of the conductive layer but not every laboratory possesses a suitable equipment. A low-cost alternative is chemical etching of the conductive layer [14], though it leads to rather inhomogeneous FTO removal. A very versatile and innovative, yet low-cost strategy is the electrochemical reductive treatment of the FTO, which leads to a clean and complete FTO removal on the exposed areas [15].

The compact n-type titanium dioxide film acts as an electronselective layer and thus prevents the recombination of excitons at the TCO surface. If this layer is absent, not dense enough or possesses pinholes, the fabricated cells will show decreased efficiencies due to recombination events. At the same time, it has to be thin enough to provide efficient electron transport by minimizing charge accumulation and therefore recombination. The so-called blocking layer can be fabricated by several ways, including, but not restricting to chemical bath deposition [16], spincoating [4], [17], spray pyrolysis [12], [18], [19], sputtering [20], [21], electron-beam evaporation [22], and atomic layer deposition [23], [24]. We decided to compare $\mathrm{TiO}_{2}$ blocking layers obtained by spray pyrolysis and spincoating of a commercial solution (Ti-Nanoxide BL/SC, Solaronix, Switzerland). An easy means to check if the electrochemical behavior of the blocking layer follows a diode-like behavior is to fabricate dummy cells. Such cells are composed of the compact $\mathrm{TiO}_{2}$ layer on top of the TCO substrate, a hole-transport layer like spiro-OMeTAD and a gold contact, thus similar to a perovskite cell, however without any photoactive layer. Cyclic voltammetry (CV) has been performed on dummy cells with different BL and the results are shown in Fig. 2(a). In the case of a BL made by spray pyrolysis, the CV shows zero anodic current and a steep increase of the cathodic current which suggests a dense and pinhole-free layer with high electronic conductivity. In case of the BL formed by spin coating, the $\mathrm{CV}$ shows, in addition to the cathodic current increase at lower potential, a sluggish cathodic and anodic current evolution across the entire potential window, which is an indication for pinholes. For comparison, the CV of a dummy cell without any blocking layer demonstrates a typical ohmic behavior, proving the absence of any blocking effect at positive potential. The PSC corresponding to the BL fabrication methods show $I-V$ curves that underline the extremely important role of the blocking layer. The cell with the BL made by spray pyrolysis shows best efficiencies, whereas that made with spincoated blocking layer performs worse. The cell without any BL shows 


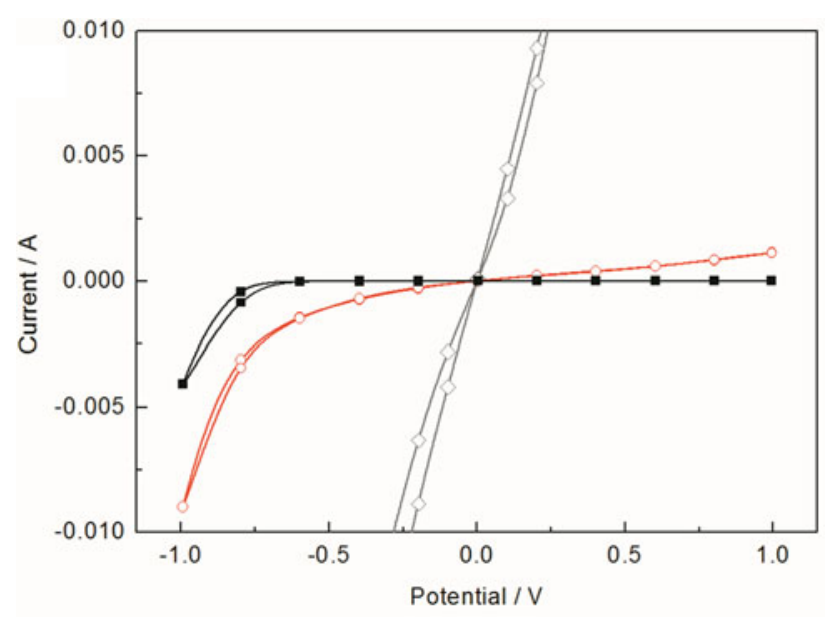

(a)

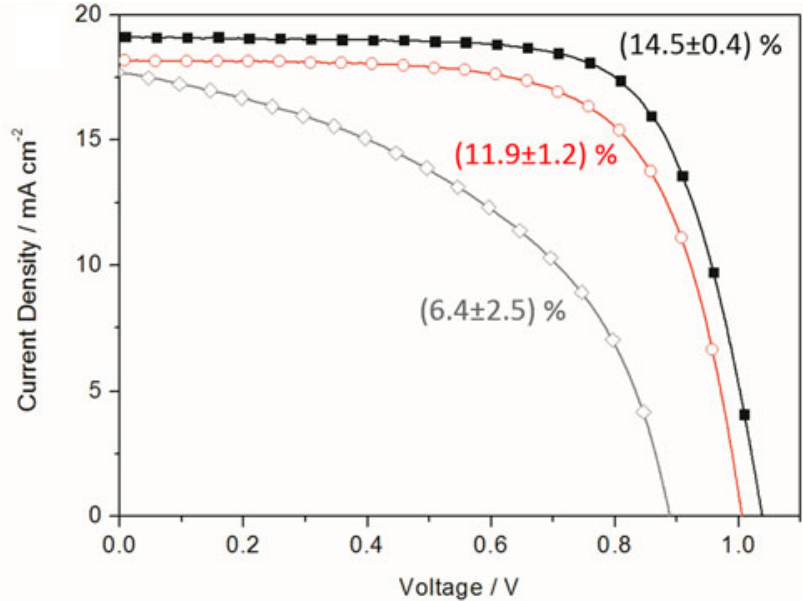

(b)

Fig. 2. (a) CV of dummy cells without blocking layer (grey diamonds), blocking layer made by spincoating (red circles) and by spray pyrolysis (black squares). (b) $I-V$ curves of PSC with a blocking layer made by spray pyrolysis (black squares), spincoating of a commercial solution (red circles) and without any blocking layer (grey diamonds) at 0.95 sun.
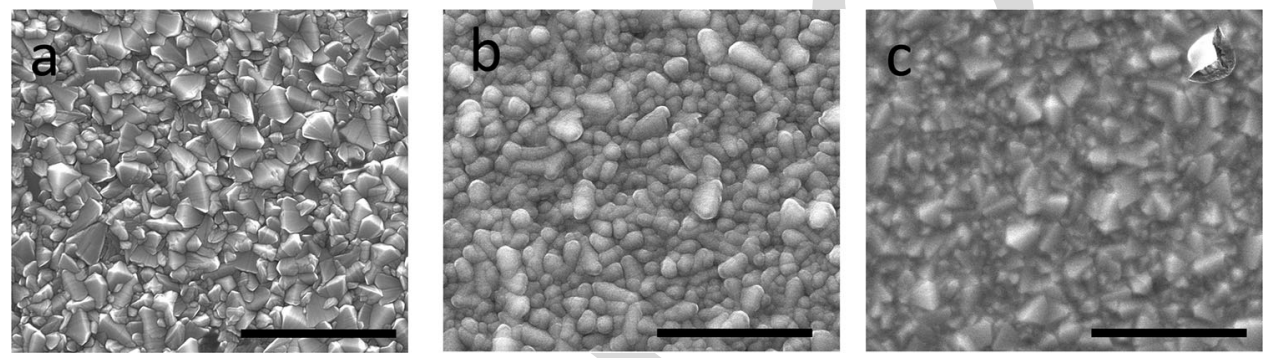

Fig. 3. (a) Scanning electron microscopy images (top-view) of a bare $\mathrm{TCO}$ substrate. (b) $\mathrm{TiO}_{2}$ compact layer deposited by spray pyrolysis. (c) Spincoating of a commercial solution. Black bars correspond to $2 \mu \mathrm{m}$.

TABLE I

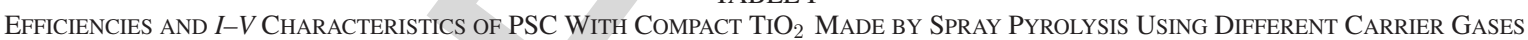

\begin{tabular}{ccccc}
\hline Spray pyrolysis carrier gas & $J_{\mathrm{sc}} / \mathrm{mA} \mathrm{cm}^{-2}$ & $V_{\mathrm{oc}} / \mathbf{V}$ & $\mathrm{FF}$ & $\eta / \%$ \\
\hline Air (best cell) & 18.6 & 1.09 & 0.76 & 15.8 \\
\hline Air (average) & & & & $15.5 \pm 0.4$ \\
\hline $\mathbf{O}_{2}$ (best cell) & 19.0 & 0.98 & 0.77 & 14.8 \\
\hline $\mathbf{O}_{2}$ (average) & & & & $14.0 \pm 0.7$ \\
\hline
\end{tabular}

the lowest efficiencies that, however, are not zero. The reason is that the perovskite layer itself is an electron transporter [17] as well as it is capable to transport holes [25], [26]. This renders the TCO-perovskite interface into a nonselective contact that promotes recombination and therefore leads to decreased efficiencies.

Images of the different blocking layers recorded by scanning electron microscopy show some fundamental differences, see Fig. 3. The layer deposited by spray pyrolysis is rather thin and homogeneous, whereas the layer deposited by spin coating is thicker and shows cracks, see Fig. 3(c) (upper right corner). It can be concluded that PSC with a BL fabricated by spray pyrolysis show superior efficiencies and therefore, this fabrication method might be recommended. The influence of the carrier gas on cell efficiencies was further tested but it came out that pure oxygen did not improve cell efficiencies, see Table I. Due to 278 lack of deposition control, BL thickness may vary between $30 \quad 279$ and $80 \mathrm{~nm}$, as occasional SEM cross sections showed. However， 280 no correlated impact on PSC efficiency could be stated. 281

Mesoporous titania layer has been employed in dye-sensitized 282 solar cells (DSSC), with the function to increase the active sur- 283 face area and transport electrons under light excitation [27]. As 284 the initial perovskite solar cells were thought as a continuity of 285 DSSC, a mesoporous titania film also was applied here, even if 286 the extinction coefficient of perovskites such as $\left(\mathrm{CH}_{3} \mathrm{NH}_{3}\right) \mathrm{PbI}_{3} \quad 287$ is about ten times higher than that of N719 dye [28]. As 288 a consequence, the necessity of active surface increase is 289 turned obsolete. Thus, PSC without mesoporous layer, so-called 290 planar devices, have been developed, though their efficiencies 291 were lagging behind those employing a mesoporous layer for 292 


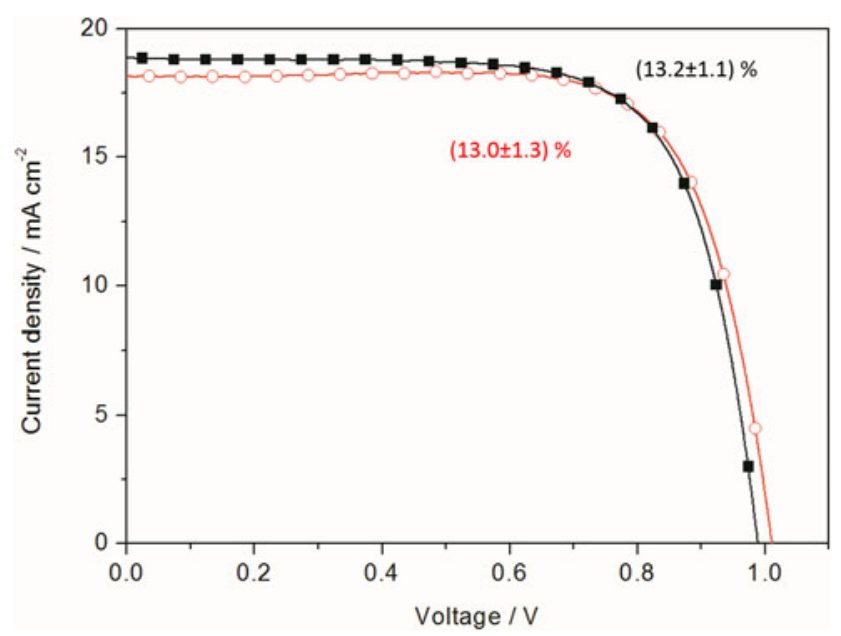

Fig. 4. $\quad I-V$ curve of cells with a mesoporous $\mathrm{TiO} 2$ layer made from $30 \mathrm{NR}$ $\mathrm{D}$ paste (average particle size of $30 \mathrm{~nm}$, black squares) and from 18-NR-T paste (average particle size of $20 \mathrm{~nm}$, red circles) at 0.94 sun. Both pastes were purchased from Dyesol Ltd.

a long time [7]. Only recently, the efficiency gap has become rather small, which is due to improved interface engineering [7], [18], [29]. Beside higher efficiencies, PSC with a mesoporous layer show reduced efficiency deviation between forward and backward scan, a phenomenon described as hysteresis [19], [30], [31]. When Snaith et al. demonstrated that even with mesoporous layers of alumina, a material that cannot participate in electron transfer due to band energy mismatch, high efficiencies of $15.9 \%$ could be obtained [32], it was deduced that the mesoporous layer mainly fulfills a structural role for crystal growth and geometry determination, even if efficient electron injection from the perovskite into the $\mathrm{TiO}_{2}$ mesoporous layer was reported [33]. However, latest results demonstrate that ionic migration at the perovskite/ $\mathrm{TiO}_{2}$ interface, which is responsible for charge accumulation and therefore recombination events, is reduced or even suppressed in the presence of the $\mathrm{TiO}_{2}$ mesoporous layer [34]. As hysteresis also depends on ionic migration [35]-[38], its reduction in the presence of mesoporous $\mathrm{TiO}_{2}$ is the consequence. Putting all together, best results have been achieved so far using a thin $\mathrm{TiO}_{2}$ mesoporous layer and a perovskite capping layer that prevents recombination between $\mathrm{TiO}_{2}$ and the hole transport layer [33], [34].

There exist several commercial pastes with different sizes of $\mathrm{TiO}_{2}$ particles and therefore, it was decided to compare two different particle sizes, namely one possessing $20 \mathrm{~nm}$ and one with $30 \mathrm{~nm}$ average particle diameter. The same paste dilution ratio in pure ethanol (1:6) as well as the same deposition and sintering conditions were applied. Fig. 4 shows that both mesoporous layers lead to very comparable cell efficiencies that are within the error scale. This points toward a higher tolerance and toward a mesoporous layer architecture, as long as the particle size remains similar.

Within perovskite materials, there exists a huge variety of recipes and deposition techniques, which are well summarized in the book by Park et al. [10] and in the review by Song et al. [39]. It might be not an easy task to decide for the suitable perovskite type and fabrication process. The name perovskite refers to a crystalline structure of the type $\mathrm{ABX}_{3}, \mathrm{~A}$ and $\mathrm{B}$ be- ing cations and $\mathrm{X}$ an anion. The perovskite class suitable for solar cells is an organic lead halide, with A being generally an organic cation, B being the lead ion, and $\mathrm{X}$ being a halogen, usually bromine, iodide, chlorine, and mixtures thereof. Lead substitution by tin and germanium analogs leads to perovskites with severe stability problems [32], [40], [41] and therefore will not be addressed here. Our focus was to determine a perovskite formulation easy to implement and that results in reproducible perovskite layers with enhanced stability. Many results have been published with monocationic perovskites, however, with some inherent limitations that are briefly exposed here: $\mathrm{MAPbI}_{3}$ has been intensively studied [42] but has some drawbacks such as weak stability toward moisture [43], [44] and temperature [45]. Formamidinium (FA) was proposed as alternative cation; however, its perovskite analog $\mathrm{FAPbI}_{3}$ crystallizes in the photoinactive phase below $60{ }^{\circ} \mathrm{C}$ [46], such as the inorganic cation analog $\mathrm{CsPbI}_{3}$ [47]. Whereas several groups observed improved stability of the photoactive phase upon using binary mixed cation perovskites [48]-[52], Saliba et al. decided to combine the three cations in a perovskite and achieved high efficiencies $(>20 \%)$ on a very reproducible basis [12].

Several methods exist for solution-processed film fabrication, the most common being simple spreading of the perovskite precursor solution on the substrate, also known as one-step deposition. However, films with poor surface control and therefore huge efficiency variations generally emerge [42]. A more sophisticated approach is the sequential step deposition, where the metal halide is first deposited and annealed before being brought in contact with the ammonium salt as vapor or in solution [42], [53]. Nevertheless, several drawbacks of this deposition method were experienced in our group, such as incomplete conversion of the metal halide or partial dissolution of the perovskite during the subsequent washing step. Furthermore, it is more time-consuming as it requires two sintering steps. The antisolvent technique was introduced in 2014 by the group of Seok [19] and since then, it has been the method of choice for subsequently published record efficiencies [7]. It is quite simple to implement and requires only one precursor solution, whereas the crystallization of the perovskite is initiated by adding a socalled antisolvent. This antisolvent is chosen not to dissolve the perovskite on one side and to displace the solvent of the latter on the other side. The main drawback of this deposition method is its artisanal aspect, requiring a certain degree of training before reaching enhanced reproducibility. However, smooth perovskite films with homogeneous composition and large grain boundaries are obtained after a short training time. Fig. 5(a) shows a cross section of a PSC with the monolithic perovskite capping layer on top of the mesoporous $\mathrm{TiO}_{2}$ layer with grains growing from the bottom to the top and which are thought to enhance charge transport, according to Saliba et al. [12]. The top view of the perovskite layer [see Fig. 5(b)] shows grains possessing diameters between 200 and $500 \mathrm{~nm}$, which is in good agreement with the original report [12].

One of the biggest detrimental factors for perovskite fabrication and stability is atmospheric humidity, together with oxygen [54]. PSC that are meant to exhibit prolonged stability require fabrication and storage in inert atmosphere or device encapsulation after fabrication [55], [56]. Therefore, PSC are 
TABLE II

Best and AVERage EfFiciencies for PSC, While the Perovskite Layer Was Fabricated Within DifFEREnt Conditions

\begin{tabular}{|c|c|c|c|c|}
\hline Perovskite fabrication condition & $J_{s c} / \mathrm{mA} \mathrm{cm}^{-2}$ & $V_{o c} / \mathrm{V}$ & $\boldsymbol{F F}$ & $\eta / \%$ \\
\hline \multirow[t]{2}{*}{$0 \%$ rel. humidity, $25^{\circ} \mathrm{C}$} & \multirow[t]{2}{*}{18.46} & \multirow[t]{2}{*}{1.06} & \multirow[t]{2}{*}{0.72} & 15.1 (best) \\
\hline & & & & $14.7 \pm 0.3$ (average) \\
\hline \multirow[t]{2}{*}{$58 \%$ rel. humidity, $25^{\circ} \mathrm{C}$} & \multirow[t]{2}{*}{16.26} & \multirow[t]{2}{*}{0.83} & \multirow[t]{2}{*}{0.67} & 9.9 (best) \\
\hline & & & & $7.4 \pm 2.4$ (average) \\
\hline \multirow[t]{2}{*}{$58 \%$ rel. humidity, $100{ }^{\circ} \mathrm{C}$} & \multirow[t]{2}{*}{17.59} & \multirow[t]{2}{*}{1.02} & \multirow[t]{2}{*}{0.57} & 10.8 (best) \\
\hline & & & & $7.4 \pm 2.6$ (average) \\
\hline
\end{tabular}
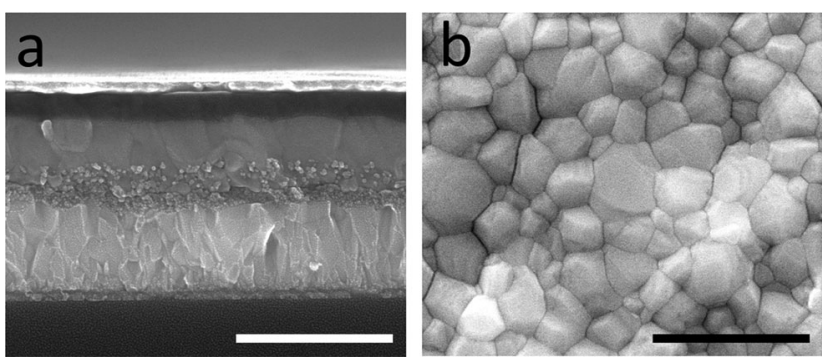

Fig. 5. SEM images. (a) Cross section of the entire PSC device showing the compact $\mathrm{TiO}_{2}$ layer (ca. $80 \mathrm{~nm}$ ), followed by the mesoporous layer of 150 $200 \mathrm{~nm}$. The adjacent perovskite layer partially infiltrates into the mesoporous structure and its capping layer has a thickness of 200-300 nm. The spiroMeOTAD hole transport layer (dark grey) has a thickness of 130-190 nm, followed by a 60-nm-thick gold layer as current collector (light grey). (b) Top view of the perovskite layer, showing grains with ca. $200-500 \mathrm{~nm}$ diameter. The fissures evolved during image capture and therefore are believed to be due to imaging. Bars correspond to $1 \mu \mathrm{m}$. generally fabricated in glove boxes with dry and oxygen-free atmosphere. And not only that, also the substrates should be absolutely moisture-free. After sintering the mesoporous layer, substrates should thus be handled only in dry atmosphere or transferred to dry atmosphere such as a glove box before cooling below $150^{\circ} \mathrm{C}$. Within the degradation mechanism of perovskite structures, oxygen only interferes subsequently to hydratation [56] and can therefore be considered less critical if moisture is absent or very low. Laboratories that are newcomers in this area of research might not possess a glove box infrastructure. Low atmospheric humidity levels are assumed to be less critical to perovskite fabrication but these conditions depend strongly on the geographic localization, the season, and some more inherent factors. To demonstrate the effect of moisture and oxygen atmosphere on perovskite formation, a comparative test of PSC devices that were fabricated inside and outside the glove box (relative humidity outside the glove box: 58\%) was performed. The results are displayed in Fig. 6 and Table II and it can be observed that in case of perovskite being fabricated in ambient atmosphere, the active layer showed a lighter color and the corresponding PSC showed a both lower $V_{\mathrm{OC}}$ and $J_{\mathrm{SC}}$, whereas the fill factor remained rather uninfluenced. As a strategy to minimize water uptake by the substrate, samples were heated to $100{ }^{\circ} \mathrm{C}$ immediately before the perovskite precursor solution was deposited. Corresponding PSC showed an improved $V_{\mathrm{OC}}$ and $J_{\mathrm{SC}}$, however the fill factor decreased. This is likely due to inhomogeneous crystal growth, induced by the elevated temperature of the substrate. For the best cells obtained, a lit-

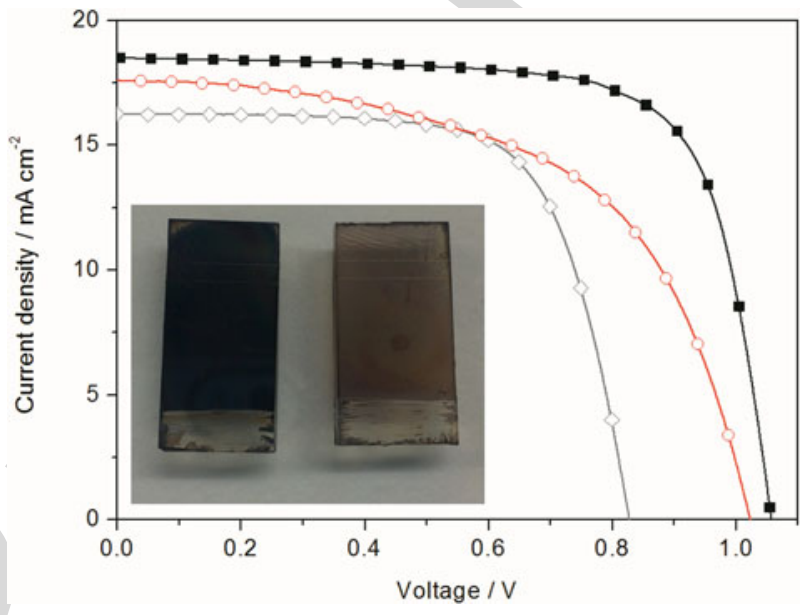

Fig. 6. $\quad I-V$ curves of PSC fabricated in a glove box with $0 \%$ relative humidity at $25^{\circ} \mathrm{C}$ (black squares), at ambient humidity $\left(58 \%\right.$ relative humidity) at $25^{\circ} \mathrm{C}$ (grey diamonds), and at ambient humidity with substrate preheating at $100{ }^{\circ} \mathrm{C}$ (red circles) with an incident light intensity of 0.94 sun. Image: Sample with perovskite produced inside (left) and outside the glove box (right) at $25^{\circ} \mathrm{C}$.

tle improvement can be stated when hot substrates were used, though average efficiencies came out to be very similar to those without heat treatment.

This study shows that it is highly recommended to work with a glove box, providing very low humidity $(<0.002 \%$ rel. humidity) and oxygen levels. Another possible strategy might be the use of a perovskite formulation that is optimized toward enhanced resistance at elevated humidity levels [57].

Atop the photoactive layer, the hole conducting layer selectively transports the holes to the current collector and therefore fulfills the complementary role to the $\mathrm{TiO}_{2}$ layer. It has to be pinhole-free to inhibit contact of the current collector with the perovskite layer, for the same reasons that were already stressed out concerning the electron conducting layer. Generally, a formulation using spiro-OMeTAD is used that contains, among others, the ionic liquid LiTFSI to increase hole conductivity. However, both LiTFSI and spiro-OMeTAD have hydrophilic properties and promote humidity ingestion, leading to poor humidity stability of the entire device. At temperatures above $55^{\circ} \mathrm{C}$, the molecular hole transporter crystallizes, which severely affects cell efficiencies. Two different hole conductor layers were compared toward their stability, namely spiro-oMeTAD as molecular HTL and poly(3-hexylthiophene) (P3HT) as polymeric HTL. 


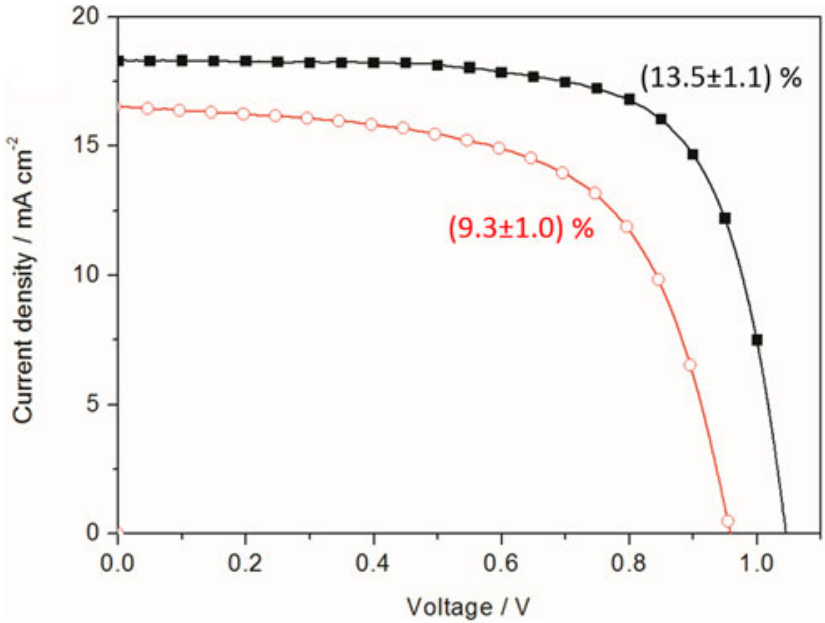

(a)

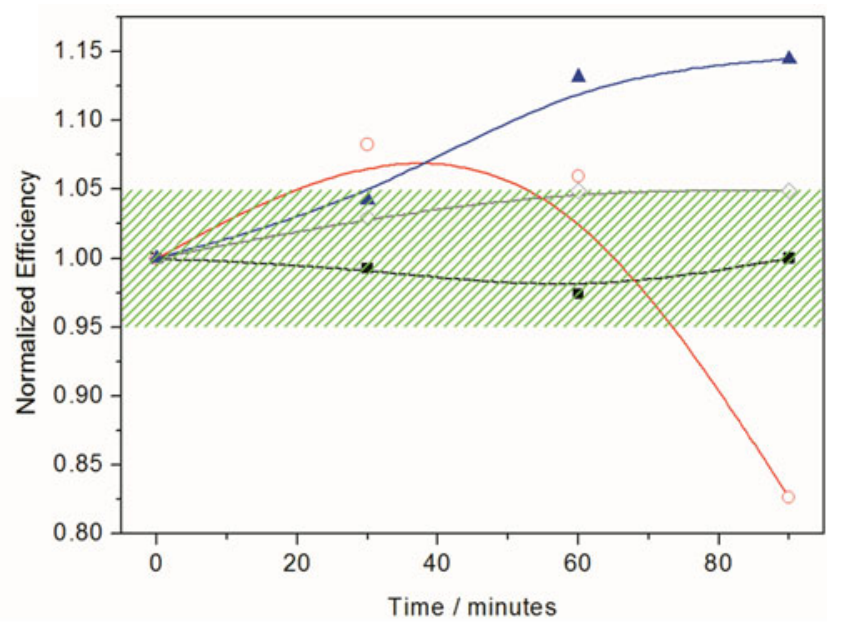

(b)

Fig. 7. (a) $I-V$ curves of PSC employing spiro-OMeTAD (black squares) and P3HT (red circles) as HTL at 0.95 sun. (b) Normalized efficiency stability of PSC using two PSC with spiro-OMeTAD (black squares and grey diamonds) and two with P3HT (red circles and blue triangles). The hatched green area indicates a deviation less than $5 \%$ from the initial efficiency.

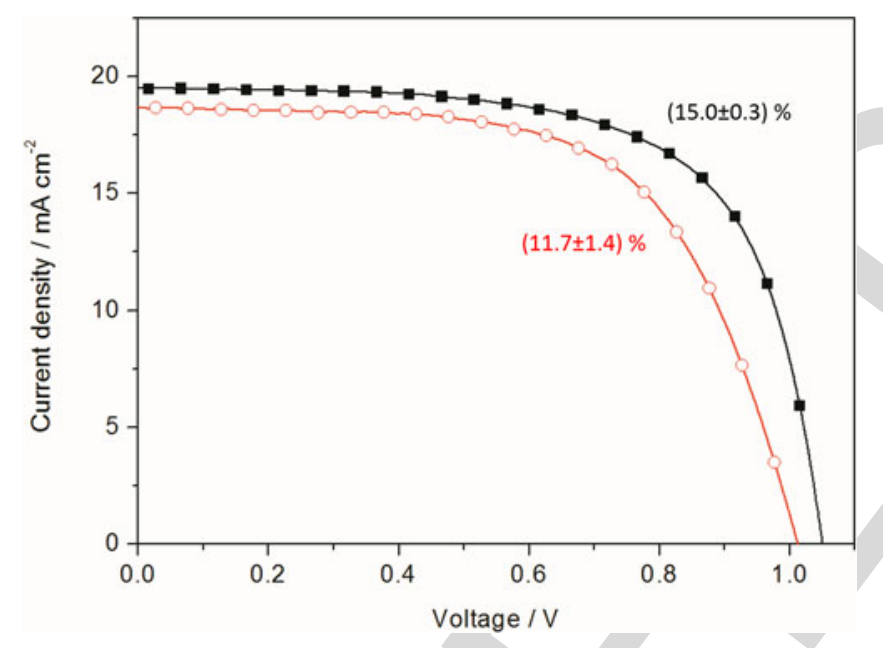

Fig. 8. $\quad I-V$ curves of PSC possessing a gold current collector made by thermal evaporation (black line) and by sputtering (red line) at 0.93 sun.
It turns out that spiro-OMeTAD leads to better efficiencies, see Fig. 7(a), showing better current density, open-circuit potential, and fill factor altogether. A potential advantage could lie in an enhanced stability despite lower efficiency when P3HT is employed, but the experimental data could not confirm this assumption, see Fig. 7(b), within the limited time frame.

Generally, current collectors are made of gold despite its higher cost, as alternative metals such as $\mathrm{Ag}$ and $\mathrm{Al}$ have been demonstrating weak stabilities [58]-[60]. Among gold deposition methods, one of the most common ones are sputtering and thermal evaporation. However, almost all published works use thermal evaporation. We decided therefore to compare gold films with similar thickness that were fabricated by these two techniques. Indeed, thermal evaporation leads to a better overall cell performance, see Fig. 8.

The reason for the worse performance of PSC with sputtered current collector was evidenced by doing a scotch test. While in case of thermal evaporation, the gold layer could be easily 457 stripped off, in case of sputtering deposition, the gold remained 458 stuck into HTM. Even after dissolving the HTM layer, gold 459 traces were still detected with the naked eye inside the per- 460 ovskite layer. This means that during the gold layer deposition, 461 surface bombardment provokes penetration of gold deep into 462 the device structure, creating recombination centers. Thus, a 463 thermal evaporator is needed for efficient perovskite solar cell 464 fabrication, even if this step considerably increases the energy 465 payback time of PSC [61].

Following all the layer fabrication steps mentioned before, it was possible to fabricate PSC with an average efficiency of $(14.8 \pm 1.0) \%$ for a set of 49 cells, see Fig. 9 left.

In laboratory conditions, cell efficiencies are generally measured for cell active areas inferior to $1 \mathrm{~cm}^{2}$. The cell area delimited by the deposition of the current collector should be only slightly superior to the active cell area (delimited by a mask) to avoid recombination events. Instead of using crocodile clamps arbitrarily connected to the cell, a suitable sample holder is preferable, see Fig. 9 right, for maximal reproducibility. Among all factors that describe the cell's performance, the maximum power point (MPP) is the most valuable information in terms of applicability in solar devices as it describes best the operating parameters of the cell [7], [13], [62]. The MPP is obtained via mathematic extraction from $I-V$ curves and surprisingly has not yet gained big attention in published scientific works. $I-V$ curves are generally obtained by dynamic scanning of external loads though care must be taken that the scan rate does not overpass the dynamic electrochemical events inside the perovskite cell. An example is given in Fig. 10, where a PSC was measured at several scan rates. If merely the $I-V$ curve is considered for efficiency determination, best results are obtained with a scan rate of $1 \mathrm{~V} / \mathrm{s}$. But if $\mathrm{CV}$ of the same cell are recorded at $10 \mathrm{mV} / \mathrm{s}$ and at $1 \mathrm{~V} / \mathrm{s}$, a striking difference is observed concerning the hysteresis, see Fig. 11. Whereas hysteresis is rather low in the former case, it considerably increases in the latter case. This 

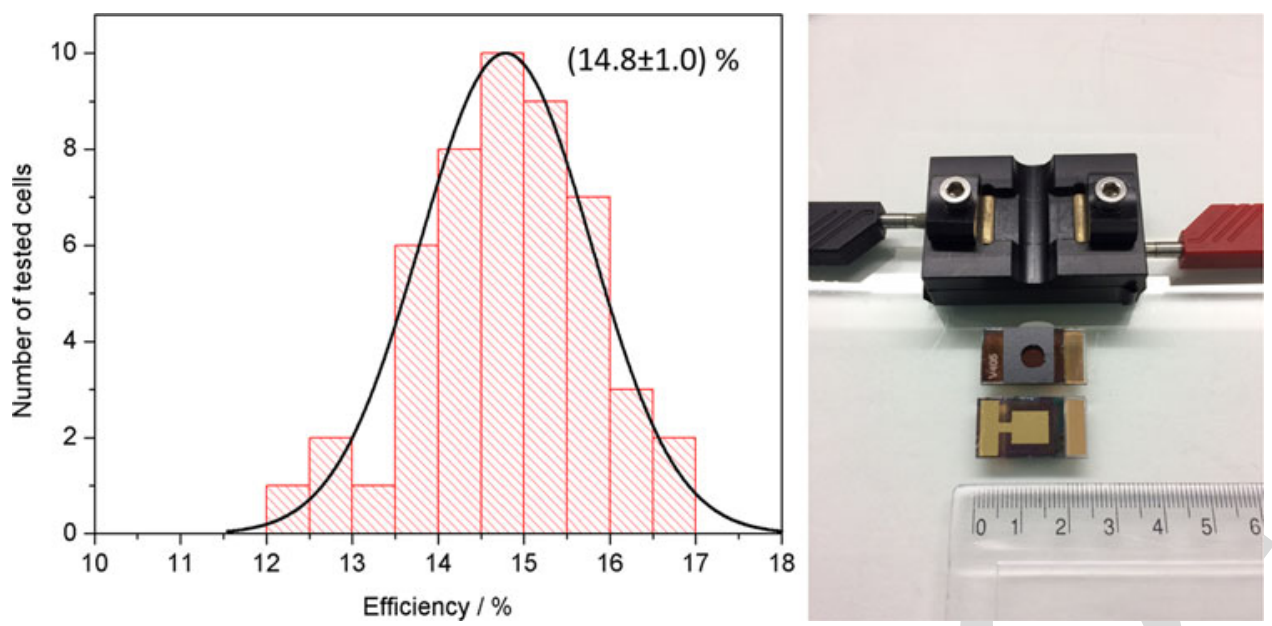

Fig. 9. Efficiency distribution of all cells fabricated in standard conditions (left) and cell architecture with testing device for reproducible testing conditions (right).

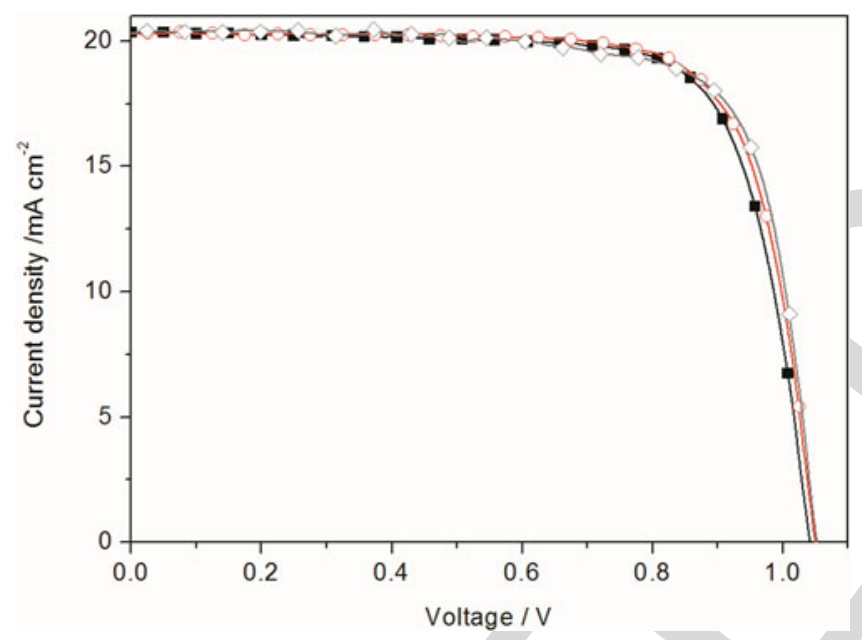

Fig. 10. $\quad I-V$ curves and efficiencies of a PSC recorded at different scan rates at 0.98 sun: $10 \mathrm{mV} / \mathrm{s}$ (black squares), $100 \mathrm{mV} / \mathrm{s}$ (red circles), $1 \mathrm{~V} / \mathrm{s}$ (grey diamonds).

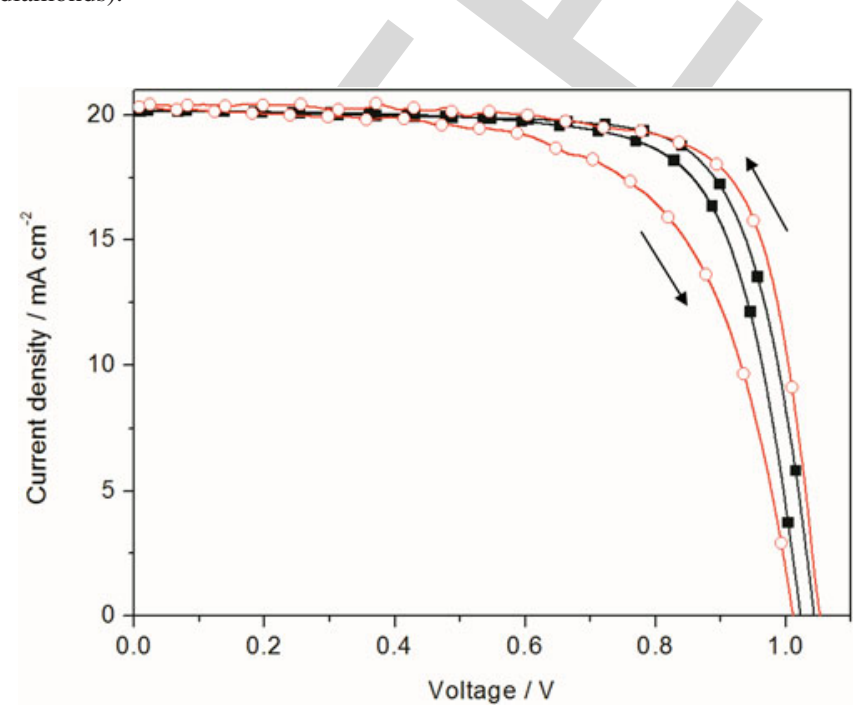

Fig. 11. Hysteresis of a PSC recorded at a scan rate of $10 \mathrm{mV} / \mathrm{s}$ (black squares) and $1 \mathrm{~V} / \mathrm{s}$ (red circles) at 0.98 sun. means that if the $I-V$ curve is recorded in backward scan in such 493 conditions, the obtained results do not reflect the cell's real be- 494 havior and therefore lead to overestimation of cell performance 495 [7], [13]. Lacking so far easily implementable measurement 496 protocols for MPP tracking, conditions for $I-V$ curve recording 497 should be carefully chosen, with the goal to not overestimate 498 real cell characteristics.

\section{CONCLUSION}

PSC represent a very attractive photovoltaic technology, as 501 innumerous publications have demonstrated, however initiating 502 in this area may be a hard task. PSC are made of several thin 503 layers and not only each layer, but also each interface plays 504 an important role for the manufacturing of efficient devices. 505 This paper is mainly directed toward research groups and sci- 506 entists that are beginners in this active field of research and as 507 such, it was intended to point out fabrication details that remain 508 barely discussed in most publications, but that are significant 509 for the preparation of efficient cells. It was evidenced that be- 510 sides the usual equipment for thin-film preparation (hot plate, 511 spin coater, programmable furnace, etc.) and photoelectrochem- 512 ical characterization (potentiostat or variable external load, solar 513 simulator), a glove box and a thermal evaporator for the depo- 514 sition of the gold current collector are strongly advised. The 515 goal of this paper is to analyze and optimize each layer and, as 516 a consequence, demonstrate their influence on the entire PSC 517 device.

It was evidenced by experiments that for PSC performing 519 best, blocking layer has to be fabricated via spray pyrolysis, 520 whereas comparable results were obtained when pure oxygen or 521 air was used as carrier gas. For the mesoporous layer, no differ- 522 ence could be stated for both particle sizes used $(20$ and $30 \mathrm{~nm}) ; 523$ however, it is likely that a bigger difference in size may be of 524 matter. Our experience showed that best results for perovskite 525 films were obtained by applying the antisolvent technique with 526 a triple cation formulation. It was demonstrated that concerning 527 the adjacent hole transport layer, spiro-OMeTAD was resulting 528 
in cells with superior efficiency compared with the polymeric analog P3HT. Finally, two techniques for the fabrication of gold current collector were presented and it was demonstrated that thermal evaporation leads to better PSC than sputtering, as in case of the latter the energetic surface bombardment provoked gold particle penetration until the perovskite active layer, thus creating recombination centers. Incorporating all the discussed optimizations, PSC with an average efficiency of $(14.8 \pm 1.0) \%$ were fabricated. Furthermore, an innovative, versatile, and quick method for electrochemical substrate etching was applied in PSC, making laser-assisted scribing and therefore the necessity of such an equipment obsolete. Dummy cells as selective electrochemical characterization method for single layers were introduced and yielded versatile results for the qualitative comparison of $\mathrm{TiO}_{2}$ blocking layers. It is believed that this paper contributes to a faster implementation of PSC fabrication in research groups with few experience in this area, thanks to a deeper understanding of fabrication details and useful analysis tools that are easily available.

\section{ACKNOWLEDGMENT}

The authors would like to thank M. Grätzel for hosting I. Mesquita at EPFL to deepen the knowledge about PSC fabrication and O. Bellon from Greatcellsolar Ltd. for fruitful discussions.

\section{REFERENCES}

[1] U.S.E.I. Administration, Washington, DC, USA, Annual Energy Outlook, 2017.

[2] I.I.R.E. Agency, Abu Dhabi, UAE, REthinking Energy 2017: Accelerating the global energy transformation, 2017.

[3] I.I.R.E. Agency, Abu Dhabi, UAE, Renewable Energy and Jobs Annual Review, 2016

[4] H.-S. Kim et al., "Lead iodide perovskite sensitized all-solid-state submicron thin film mesoscopic solar cell with efficiency exceeding 9\%," Sci. Rep., vol. 2, 2012, Art. no. 591

[5] NREL efficiency chart. [Online.] Available: https://www.nrel.gov/pv/ assets/images/efficiency-chart.png. Accessed on: Mar. 26, 2018.

[6] [Online.] Available: http://www.greatcellsolar.com/wp-content/uploads/ 2018/03/Aurora-Newsletter-March-2018-Final-ENG-RC.pdf

[7] J.-P. Correa-Baena et al., "The rapid evolution of highly efficient perovskite solar cells," Energy Environ. Sci., vol. 10, pp. 710-727, 2017.

[8] T. Salim, S. Sun, Y. Abe, A. Krishna, A. C. Grimsdale, and Y. M. Lam, "Perovskite-based solar cells: Impact of morphology and device architecture on device performance," J. Mater. Chem. A, vol. 3 pp. 8943-8969, 2015.

[9] I. Mesquita, L. Andrade, and A. Mendes, "Perovskite solar cells: Materials, configurations and stability," Renewable Sustain. Energy Rev., vol. 82, pp. $2471-2489,2018$

[10] N. G. Park, M. Grätzel, and T. Miyasaka, Organic-Inorganic Halide Perovskite Photovoltaics: From Fundamentals to Device Architectures. New York, NY, USA: Springer, 2016.

[11] C. C. Wu, C. I. Wu, J. C. Sturm, and A. Kahn, "Surface modification of indium tin oxide by plasma treatment: An effective method to improve the efficiency, brightness, and reliability of organic light emitting devices," Appl. Phys. Lett., vol. 70, pp. 1348-1350, 1997.

[12] M. Saliba et al., "Cesium-containing triple cation perovskite solar cells: Improved stability, reproducibility and high efficiency," Energy Environ. Sci., vol. 9, pp. 1989-1997, 2016.

[13] J. A. Christians, J. S. Manser, and P. V. Kamat, "Best practices in perovskite solar cell efficiency measurements. Avoiding the error of making bad cells look good," J. Phys. Chem. Lett., vol. 6, , pp. 852-857, 2015.

[14] H.-R. Xia, J. Li, W.-T. Sun, and L.-M. Peng, "Organohalide lead perovskite based photodetectors with much enhanced performance," Chem. Commun., vol. 50, pp. 13695-13697, 2014.
[15] S. P. Koiry et al., "An electrochemical method for fast and controlled etching of fluorine-doped tin oxide coated glass substrates," J. Electrochem. Soc., vol. 164, pp. E1-E4, 2017.

[16] G. Yin et al., "Enhancing efficiency and stability of perovskite solar cells through $\mathrm{Nb}$-doping of $\mathrm{TiO} 2$ at low temperature," ACS Appl. Mater Interfaces, vol. 9, pp. 10752-10758, 2017.

[17] M. Liu, M. B. Johnston, and H. J. Snaith, "Efficient planar heterojunction perovskite solar cells by vapour deposition," Nature, 501, pp. 395-398, 2013.

[18] D. Bi et al., "Polymer-templated nucleation and crystal growth of perovskite films for solar cells with efficiency greater than $21 \%$," Nature Energy, vol. 1, 2016, Art. no. 16142.

[19] N. J. Jeon, J. H. Noh, Y. C. Kim, W. S. Yang, S. Ryu, and S. I. Seok, "Solvent engineering for high-performance inorganic-organic hybrid perovskite solar cells," Nature Mater, vol. 13, pp. 897-903, 2014.

[20] D. Yang, Z. Yang, W. Qin, Y. Zhang, S. Liu, and C. Li, "Alternating precursor layer deposition for highly stable perovskite films towards efficient solar cells using vacuum deposition," J. Mater. Chem. A, vol. 3, pp. 9401-9405, 2015.

[21] D. Yang et al., "Surface optimization to eliminate hysteresis for record efficiency planar perovskite solar cells," Energy Environ. Sci., vol. 9, pp. 3071-3078, 2016.

[22] K. Wang et al., "CO2 Plasma-treated $\mathrm{TiO} 2$ film as an effective electron transport layer for high-performance planar perovskite solar cells," ACS Appl. Mater. Interfaces, vol. 9, pp. 33989-33996, 2017.

[23] W. Yongzhen et al.,"Highly compact TiO 2 layer for efficient holeblocking in perovskite solar cells," Appl. Phys. Express, vol. 7, 2014, Art. no. 052301.

[24] $\mathrm{H}$. Hu et al., "Atomic layer deposition of $\mathrm{TiO} 2$ for a high-efficiency holeblocking layer in hole-conductor-free perovskite solar cells processed in ambient air," ACS Appl. Mater. Interfaces, vol. 8, pp. 17999-18007, 2016.

[25] L. Etgar, Hole Transport Material (HTM) Free Perovskite Solar Cell, Hole Conductor Free Perovskite-Based Solar Cells. Cham, Switzerland: Springer, 2016, pp. 9-24.

[26] L. Etgar et al., "Mesoscopic $\mathrm{CH} 3 \mathrm{NH} 3 \mathrm{PbI} 3 / \mathrm{TiO} 2$ heterojunction solar cells," J. Amer. Chem. Soc., vol. 134, pp. 17396-17399, 2012.

[27] A. Hagfeldt, G. Boschloo, L. Sun, L. Kloo, and H. Pettersson, "Dyesensitized solar cells," Chem. Rev., vol. 110, pp. 6595-6663, 2010.

[28] J.-H. Im, C.-R. Lee, J.-W. Lee, S.-W. Park, and N.-G. Park, "6.5\% efficient perovskite quantum-dot-sensitized solar cell," Nanoscale, vol. 3 pp. 4088-4093, 2011.

[29] E. H. Anaraki et al., "Highly efficient and stable planar perovskite solar cells by solution-processed tin oxide," Energy Environ. Sci., vol. 9 , pp. 3128-3134, 2016.

[30] H. J. Snaith et al., "Anomalous hysteresis in perovskite solar cells," $J$. Phys. Chem. Lett., vol. 5, pp. 1511-1515, 2014.

[31] B. Chen, M. Yang, S. Priya, and K. Zhu, "Origin of J-V hysteresis in perovskite solar cells," J. Phys. Chem. Lett., vol. 7, pp. 905-917, 2016.

[32] K. Wojciechowski, M. Saliba, T. Leijtens, A. Abate, and H. J. Snaith, "Sub150 [degree]C processed meso-superstructured perovskite solar cells with enhanced efficiency," Energy Environ. Sci., vol. 7, pp. 1142-1147, 2014.

[33] T. Leijtens, B. Lauber, G. E. Eperon, S. D. Stranks, and H. J. Snaith, "The importance of perovskite pore filling in organometal mixed halide sensitized TiO2-based solar cells," J. Phys. Chem. Lett., vol. 5, pp. 10961102, 2014.

[34] M. Anaya et al., "Electron injection and scaffold effects in perovskite solar cells," J. Mater. Chem. C, vol. 5, pp. 634-644, 2017.

[35] E. L. Unger et al., "Hysteresis and transient behavior in current-voltage measurements of hybrid-perovskite absorber solar cells," Energy Environ. Sci., vol. 7 pp. 3690-3698, 2014.

[36] W. Tress, N. Marinova, T. Moehl, S. M. Zakeeruddin, M. K. Nazeeruddin, and M. Gratzel, "Understanding the rate-dependent J-V hysteresis, slow time component, and aging in $\mathrm{CH} 3 \mathrm{NH} 3 \mathrm{PbI} 3$ perovskite solar cells: The role of a compensated electric field," Energy Environ. Sci., vol. 8, pp. 9951004, 2015.

[37] S. Meloni et al., "Ionic polarization-induced current-voltage hysteresis in CH3NH3PbX3 perovskite solar cells," Nature Commun., vol. 7, 2016 Art. no. 10334

[38] G. Richardson et al., "Can slow-moving ions explain hysteresis in the current-voltage curves of perovskite solar cells?" Energy Environ. Sci., vol. 9, pp. 1476-1485, 2016.

[39] Z. Song, S. C. Watthage, A. B. Phillips, and M. J. Heben, "Pathways toward high-performance perovskite solar cells: Review of recent advances in organo-metal halide perovskites for photovoltaic applications," J. Photon. Energy, vol. 6, 2016, Art. no. 022001. 
[40] F. Hao, C. C. Stoumpos, D. H. Cao, R. P. H. Chang, and M. G. Kanatzidis, "Lead-free solid-state organic-inorganic halide perovskite solar cells," Nature Photon., vol. 8, pp. 489-494, 2014.

[41] T. Krishnamoorthy et al.,"Lead-free germanium iodide perovskite materials for photovoltaic applications," J. Mater. Chem. A, vol. 3, pp. 2382923832, 2015.

[42] J. Burschka et al., "Sequential deposition as a route to high-performance perovskite-sensitized solar cells," Nature, vol. 499 pp. 316-319, 2013.

[43] M. A. Green, A. Ho-Baillie, and H. J. Snaith, "The emergence of perovskite solar cells," Nature Photon., vol. 8pp. 506-514, 2014.

[44] M. Gratzel, "The light and shade of perovskite solar cells," Nature Mater. vol. 13, pp. 838-842, 2014.

[45] B. Conings et al., "Intrinsic thermal instability of methylammonium lead trihalide perovskite," Adv. Energy Mater., vol. 5, 2015, Art. no. 1500477.

[46] C. C. Stoumpos, C. D. Malliakas, and M. G. Kanatzidis, "Semiconducting tin and lead iodide perovskites with organic cations: Phase transitions, high mobilities, and near-infrared photoluminescent properties," Inorganic Chem., vol. 52, pp. 9019-9038, 2013.

[47] C. K. Moller, "Crystal structure and photoconductivity of caesium plumbohalides," Nature, vol. 182, pp. 1436-1436, 1958.

[48] N. J. Jeon et al., "Compositional engineering of perovskite materials for high-performance solar cells," Nature, vol. 517, pp. 476-480, 2015.

[49] J. P. Correa Baena et al., "Highly efficient planar perovskite solar cells through band alignment engineering," Energy Environ. Sci., vol. 8, pp. 2928-2934, 2015.

[50] H. Choi et al., "Cesium-doped methylammonium lead iodide perovskite light absorber for hybrid solar cells," Nano Energy, vol. 7, pp. 80-85, 2014.

[51] J.-W. Lee, D.-H. Kim, H.-S. Kim, S.-W. Seo, S. M. Cho, and N.-G. Park, "Formamidinium and cesium hybridization for photo- and moisture-stable perovskite solar cell," Adv. Energy Mater., vol. 5, 2015, Art. no. 1501310.

[52] X. Li et al., "A vacuum flash-assisted solution process for high-efficiency large-area perovskite solar cells," Science, vol. 353, pp. 58-62, 2016.

[53] Q. Chen et al., "Planar heterojunction perovskite solar cells via vaporassisted solution process," J. Amer. Chem. Soc., vol. 136, pp. 622-625, 2014.

[54] T. Leijtens, G. E. Eperon, N. K. Noel, S. N. Habisreutinger, A. Petrozza, and H. J. Snaith, "Stability of metal halide perovskite solar cells," Adv. Energy Mater, vol. 5, 2015.

[55] F. Matteocci et al., "Encapsulation for long-term stability enhancement of perovskite solar cells," Nano Energy, vol. 30, pp. 162-172, 2016.

[56] I. Mesquita, L. Andrade, and A. Mendes, "Perovskite solar cells: Materials, configurations and stability," Renewable Sustain. Energy Rev., vol. 82 pp. 2471-2489, 2017.

[57] Q. Tai et al., "Efficient and stable perovskite solar cells prepared in ambient air irrespective of the humidity," Nature Commun., vol. 7, 2016, Art. no. 11105.

[58] T. Leijtens, G. E. Eperon, S. Pathak, A. Abate, M. M. Lee, and H. J. Snaith, "Overcoming ultraviolet light instability of sensitized $\mathrm{TiO} 2$ with meso-superstructured organometal tri-halide perovskite solar cells," $\mathrm{Na}$ ture Commun., vol. 4, 2013, Art. no. 2885.

[59] Y. Han et al., "Degradation observations of encapsulated planar $\mathrm{CH} 3 \mathrm{NH} 3 \mathrm{PbI} 3$ perovskite solar cells at high temperatures and humidity," J. Mater. Chem. A, vol. 3, pp. 8139-8147, 2015.

[60] J. You et al., "Improved air stability of perovskite solar cells via solutionprocessed metal oxide transport layers," Nature Nanotechnol., vol. 11, pp. 75-81, 2016.

[61] J. Gong, S. B. Darling, and F. You, "Perovskite photovoltaics: Life-cycle assessment of energy and environmental impacts," Energy Environ. Sci., vol. 8, pp. 1953-1968, 2015.

[62] E. Zimmermann et al., "Characterization of perovskite solar cells: Towards a reliable measurement protocol," APL Mater, vol. 4, 2016, Art. no. 091901.

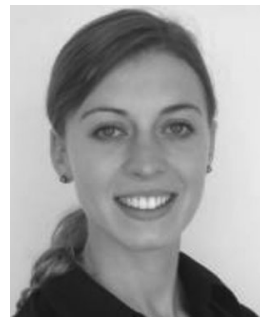

Verena Stockhausen received the B.S. degree in 730 chemistry and biochemistry and the M.S. degree 731 in chemistry from Ludwig Maximilians University, 732 Munich, Germany, in 2005 and 2007, respectively, 733 and the Ph.D. degree in analytical physical chem- 734 istry from Denis Diderot University, Paris, France, 735 in 2011.

In 2013 and from 2015 to 2017, she was a Post- 737 doc Fellow within the group of Prof. Adélio Mendes. 738 Her research interests include photovoltaic systems 739 such as dye-sensitized solar cells and perovskite so- 740 lar cells, as well as photoelectrochemical systems for water splitting.

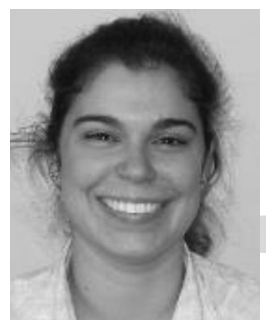

Isabel Mesquita was born in Porto, Portugal, in 1988. 743 She received the M.S. degree in chemical engineer- 744 ing from the University of Porto, Porto, in 2011. She 745 is currently working toward the Ph.D. degree at the 746 Faculty of Engineering, University of Porto, focusing 747 in the perovskite solar cells and their stability. $\quad 748$

From September of 2011 to March 2015, she 749 was a Research Fellow with LEPABE-Laboratory 750 for Process Engineering, Environment, Biotechnol- 751 ogy and Energy working in methanol fuel cells and 752 dye-sensitized solar cells. .
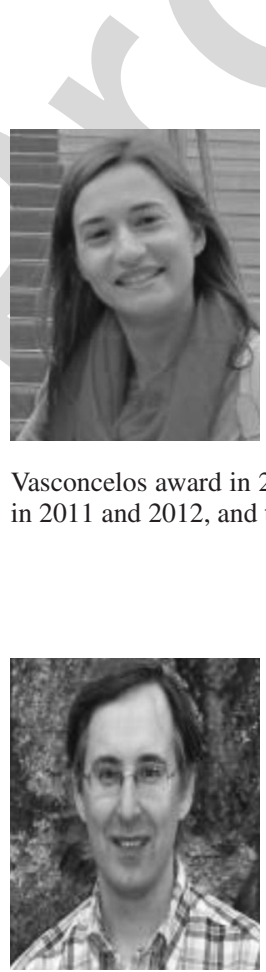

Adélio Mendes was born in 1964. He received the 769 Ph.D. degree from the University of Porto, Porto, Por- 770 tugal, in 1993.

He is a Full Professor with the Chemical Engineer- 772 ing Department, Faculty of Engineering, University 773 of Porto. He coordinates a large research team with re- 774 search interests mainly including dye-sensitized solar 775 cells and perovskite solar cells, photoelectrochemi- 776 cal cells, including water splitting and solar redox 777 flow cells, redox flow batteries, PEMFC, methanol 778 steam reforming, membrane, and adsorbent-based 779 gas separations. He received an Advanced Research Grant from the ERC on 780 dye-sensitized solar cells for building integrated of ca. 2 MEuros. He is cur- 781 rently the Coordinator of CEner-FEUP, the Competence Center for Energy of 782 the Faculty of Engineering at the University of Porto. , 77 773 75

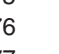

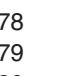

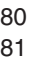


- Authors: Please note that we cannot accept new source files as corrections for your paper. If possible, please annotate the PDF proof we have sent you with your corrections, using Adobe Acrobat editing software, and upload it via the Author Gateway. Alternatively, you may send us your corrections in a simple .txt file, utilizing the line numbers in the margins of the proof to indicate exactly where you would like for us to make corrections. You may, however, upload revised graphics via the Author Gateway.

\section{QUERIES}

Q1. Author: Please check whether the funding information is correct.

Q2. Author: Please provide the expansion of DMF, DMSO, and HTL.

Q3. Author: Please check the usage of the term "hydratation" in the sentence "Within the degradation mechanism of perovskite structures ...".

Q4. Author: Please provide missing year for Refs. [5] and [6].

Q5. Author: Please provide page rage for Ref. [54]. 


\title{
Insights in Perovskite Solar Cell Fabrication: Unraveling the Hidden Challenges of Each Layer
}

\author{
Verena Stockhausen, Isabel Mesquita, Luísa Andrade, and Adélio Mendes (®)
}

\begin{abstract}
Perovskite solar cells (PSC) are undoubtedly the most active research area in photovoltaics at this moment. Actually, since 2009 this emerging technology passed from $3.8 \%$ to the present $>22 \%$ of energy conversion efficiency. Along with that, a huge amount of sometimes contradicting and incomplete information about how to prepare and characterize PSC is provided, which makes it difficult to not get lost. This paper is mainly directed toward newcomers in this area, with the goal to give orientation for PSC fabrication protocols that are quickly implementable and that lead to reliable and acceptable efficiencies. Therefore, a step-by-step analysis of each layer is provided and, within this scope, several fabrication techniques are compared in terms of efficiency optimization. Furthermore, a new and versatile alternative to laser-assisted scribing for substrate patterning is presented. Electrochemical characterization of dummy cells as an easy and versatile tool for isolated layer characterization is demonstrated for $\mathrm{TiO}_{2}$ blocking layers. After optimization of each layer, PSC with an average efficiency of $(14.8 \pm 1.0) \%$ was obtained.
\end{abstract}

Index Terms-Blocking layer, fabrication details, performance, perovskite solar cells.

\section{INTRODUCTION}

$\mathbf{G}$ LOBAL energy consumption is projected to raise by $48 \%$ from 2012 to 2040 [1], which makes the intensification of renewable energy implementation unavoidable. Among them, solar energy production has been the fastest growing sector with the biggest share in newly created jobs in the past few

Manuscript received December 22, 2017; revised April 4, 2018; accepted April 6, 2018. This work was supported in part by the European Union's Horizon 2020 Programme, through a FET Open research and innovation action under Grant 687008, in part by the Project POCI-01-0145-FEDER-006939 (LEPABE - Laboratory for Process Engineering, Environment, Biotechnology and Energy - UID/EQU/00511/2013), funded by the European Regional Development Fund, through COMPETE2020 - Programa Operacional Competitividade e Internacionalização (POCI) and by nationals funds through FCT (Fundação para a Ciência e a Tecnologia), and in part by NORTE-01-0145-FEDER-000005 - LEPABE-2-ECO-INNOVATION, supported by North Portugal Regional Operational Programme (Norte 2020), under the Portugal 2020 Partnership Agreement, through the European Regional Development Fund. The work of V. Stockhausen was supported by the European Commission through the Seventh Framework Program, the Specific Program "Ideas" of the European Research Council for research and technological development as part of an Advanced Grant under Grant 321315 (BI-DSC). The work of I. Mesquita was supported by the FCT for her Ph.D. fellow (ref.: PD/PB/105985/2014). The work of L. Andrade was supported by the FCT (IF/01331/2015). (Corresponding author: Adélio Mendes.)

The authors are with the Faculdade de Engenharia, Universidade do Porto, Porto 4200-465, Portugal (e-mail: verena@ fe.up.pt; mesquita@fe.up.pt; landrade@fe.up.pt; mendes@fe.up.pt).

Color versions of one or more of the figures in this paper are available online at http://ieeexplore.ieee.org.

Digital Object Identifier 10.1109/JPHOTOV.2018.2826055 years [2], [3]. Besides the mature silicon technology, advanced copper indium gallium selenide and CdTe solar cells lately entering the market, perovskite solar cells (PSC) have been earning a lot of attention due to their striking performance evolution since 2012 [4]. Since then, PSC efficiencies have been ramping up quickly, reaching certified record efficiencies of $22.7 \%$ for laboratory devices [5]; more recently, in February 2018, Grätzel reported 23.3\% at ABXPV conference, Rennes [6]. Despite the fast progress in fabricating PSC with high efficiency, stability has been a limiting factor so far. Thus, attempting to address efficiency and stability, a huge variety of formulations and cell architectures has been published. It includes planar devices using an inverted $\mathrm{p}-\mathrm{i}-\mathrm{n}$ architecture and PSC employing a mesoporous structure that can either actively participate in the electron transfer (active mesoporous layer) or merely serve as scaffold structure (passive mesoporous layer). Within perovskites, chemical engineering has originated a huge quantity of mixed structures, employing mixed cations and anions. Many laboratories have been deciding to direct research efforts toward this "shooting star," but not all of them were capable to reproduce the outstanding results published in the literature. Even without regarding long-term stability, efficiencies often remain below expectations because usually, crucial technical details remain barely explained or even unmentioned in research articles. Thus, little fabrication errors within each layer of the PSC will sum up and lead to an overall efficiency drop. Therefore, merely considering efficiencies of entire devices makes reproduction of published results a hard task.

In this paper, a step-by-step analysis of the technical problems of each layer is provided and a possible impact of their modification on the cell performance will be assessed. In the end, the characterization of the entire device is discussed. As record efficiency PSC's generally possess a cell architecture with an active mesoporous layer [7], focus will lie on this PSC structure. For a deeper discussion about alternative cell architectures, interested readers are referred to the informative review of Salim et al. [8], Mesquita et al. [9] or the recent book written by Park et al. [10].

\section{Materials AND MethodS}

Fig. 1 shows a schematic representation of the PSC. On top of a transparent conductive oxide (TCO) substrate that was scribed in order to impede shortcircuiting (grey line), a dense $\mathrm{TiO}_{2}$ layer is deposited, followed by a mesoporous layer. The adjacent perovskite layer partially infiltrates into the mesoporous structure and forms a capping layer. It is followed by a layer of hole 

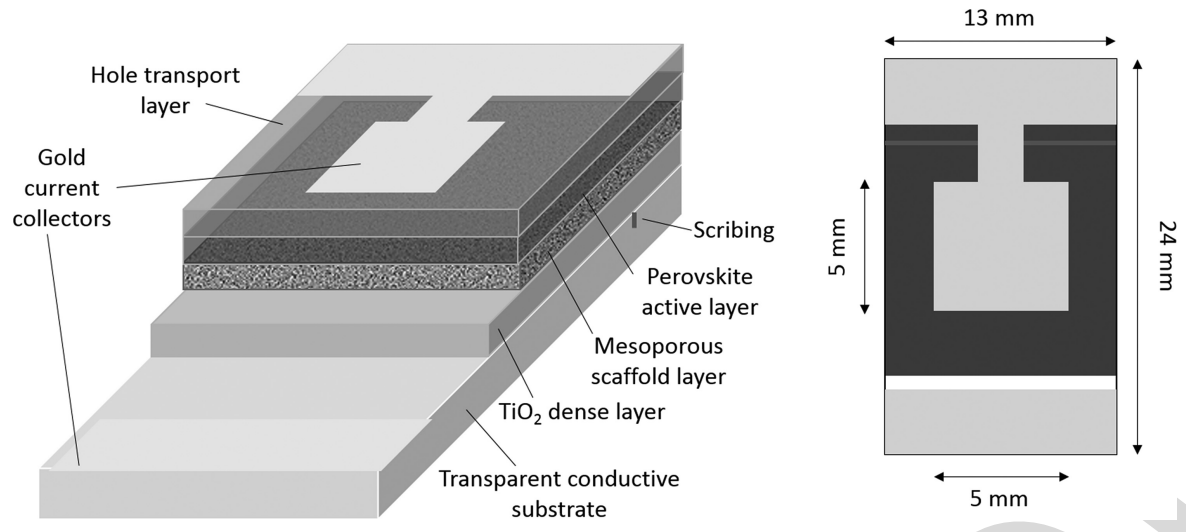

Fig. 1. Schematic representation of a mesoscopic PSC in cross section (left) and top view (right).

transport material (HTM); finally, a nanometric metallic layer serves as a current collector.

In the following, layer fabrication details and, when applicable, alternative fabrication methods are presented. Furthermore, it will be discussed what equipment is required for cell fabrication and which equipment acquisition can be postponed, thanks to alternative fabrication protocols.

\section{A. Substrate Preparation}

Fluoride-doped tin oxide (FTO) substrates $(2.2 \mathrm{~mm}$ thickness, TEC7, Solaronix) were patterned via VersaLaser (VLS 2.30, Universal Laser Systems, USA) to create two separate charge collection areas on the FTO substrate-method (A). As an alternative to laser scribing, which requires the availability of such an equipment, an electrochemical reductive treatment can be performed to remove selectively the conductive layermethod (B). Keep into consideration that the chemicals used for that purpose are highly corrosive, which requires adequate protection and care. In order to do so, the substrate area for TCO removal was delimited by Kapton tape and exposed to a $3 \mathrm{M}$ $\mathrm{HCl}$ solution. A constant potential of $-2.4 \mathrm{~V}$ was applied until cathodic current decrease started to flatten. Meanwhile, the tin oxide of the FTO turned grey and started to peel off; samples were removed from the solution and rinsed with water. With a cotton swab dipped in a diluted nitric acid solution $(0.5 \mathrm{M})$, remaining tin residues were cleaned off. Then, Kapton tape was removed and samples were abundantly rinsed with water.

In a next step, samples were mechanically cleaned, using a toothbrush and a $10 \%$ Hellmanex III (Hellma GmbH, Germany) solution. Subsequently, substrates were abundantly rinsed with water and sonicated in ethanolic $\mathrm{KOH}$ solution for $5 \mathrm{~min}$. The substrates were again abundantly rinsed with water and sonicated in water for $5 \mathrm{~min}$, before being rinsed with acetone and dried in nitrogen flux. Prior to blocking layer deposition, substrates were additionally cleaned for $20 \mathrm{~min}$ by an ozone cleaner (UVO-Cleaner, Jelight Company Inc., USA). Alternatively to an ozone cleaner, plasma treatment can be applied [11], among other efficient methods.

\section{B. Electron Blocking (BL) and Mesoporous Layer Preparation}

$\mathrm{TiO}_{2}$ blocking layer was deposited by two different methods. Method (A) was done by spincoating of a commercial solution
(Ti-Nanoxide BL/SC, Solaronix, Switzerland) $(5000 \mathrm{r} / \mathrm{min}, 30 \mathrm{~s}$, $2000(\mathrm{r} / \mathrm{min}) / \mathrm{s})$. Before film deposition, the area of photoanode contact was protected by adhesive strip (Scotch Magic Tape, $3 \mathrm{M}$ ) and the films were subsequently calcined at $550{ }^{\circ} \mathrm{C}$ for $1 \mathrm{~h}$, under application of a stepwise temperature increase of $100{ }^{\circ} \mathrm{C}$ each $10 \mathrm{~min}$. Method (B) employed spray pyrolysis of a precursor solution containing $0.56 \mathrm{M}$ acetylacetone (Sigma-Aldrich, 99.6\%) and 0.18 M titanium diisopropoxide bis(acetylacetonate) (Sigma-Aldrich, $75 \mathrm{wt} . \%$ in isopropanol) in $7 \mathrm{~mL}$ isopropanol (Sigma-Aldrich, anhydrous, 99.5\%) that was sufficient for 64 samples. Here, substrates were preheated at $450{ }^{\circ} \mathrm{C}$ and the photoanode area was protected with a glass stripe before applying the spray via an atomizer, using either air or oxygen as carrier gas. Afterward, samples were left for $45 \mathrm{~min}$ more at that temperature. For application of mesoporous $\mathrm{TiO}_{2}$, a commercial paste (generally 30-NR-D, Dyesol, Australia, unless otherwise stated) was diluted in pure ethanol $(1: 6 \mathrm{w} / \mathrm{w})$ and applied on the substrates via spincoating $(5000 \mathrm{r} / \mathrm{min}, 10 \mathrm{~s}, 2000$ $(\mathrm{r} / \mathrm{min}) / \mathrm{s})$. Prior to deposition, photoanode contact had been protected by adhesive stripes. Samples were then immediately transferred on a heat plate at $100{ }^{\circ} \mathrm{C}$ for predrying before being calcined in a furnace at $500{ }^{\circ} \mathrm{C}$ for $30 \mathrm{~min}$. Subsequently, samples were transferred to oxygen-free and dry conditions (glove box) before allowing to cool below $100{ }^{\circ} \mathrm{C}$

\section{Perovskite Active Layer Preparation}

The perovskite precursor solution was prepared according to the following conditions published by Saliba et al. [12]: 1.1 M $\mathrm{PbI}_{2}$ (Sigma-Aldrich, 99.999\% trace metal basis), $0.2 \mathrm{M} \mathrm{PbBr}_{2}$ (Sigma-Aldrich, 99.999\% trace metal basis), $0.2 \mathrm{M}$ methylammonium bromide (Dyesol), and $1.0 \mathrm{M}$ formamidinium iodide (Dyesol) were dissolved in $1 \mathrm{~mL}$ of a DMF/DMSO mixture ( $8: 2$ v/v, both Sigma-Aldrich, 99.8 and $\geq 99.9 \%$, respectively). From this solution, $0.95 \mathrm{~mL}$ were added to $0.05 \mathrm{~mL}$ of a $1.5 \mathrm{M} \mathrm{CsI}$ stock solution in DMSO (Sigma-Aldrich, 99.999\% trace metals basis). This final solution was deposited on the substrates by applying a two-step spincoating program (step 1: $1000 \mathrm{r} / \mathrm{min}$, $10 \mathrm{~s}, 200(\mathrm{r} / \mathrm{min}) / \mathrm{s}$, step 2: $6000 \mathrm{r} / \mathrm{min}, 30 \mathrm{~s}, 2000(\mathrm{r} / \mathrm{min}) / \mathrm{s})$. After $25 \mathrm{~s}, 100 \mu \mathrm{L}$ chlorobenzene was poured onto the spinning substrate, a procedure which is known as antisolvent technique. Careful adjustment of dripping speed and tip-to-sample distance had to be trained to fabricate samples in a reproducible manner. 
Samples appeared brown immediately after spincoating and were subsequently sintered at $100{ }^{\circ} \mathrm{C}$ for $40 \mathrm{~min}$ before being allowed to cool down. After each deposition, the interior of the spin coater was cleaned with a cloth to remove the condensed chemicals.

\section{Hole Conducting Layer and Current Collector}

Two different hole conductors were tested: method (A) spiro-OMeTAD solution contained $75 \mathrm{mM}$ spiroOMeTAD (Chemborun, 99.7\% sublimed grade), $0.24 \mathrm{M}$ 4-tert-butylpyridine (Sigma-Aldrich, $96 \%$ ), $41 \mathrm{mM}$ lithium bistrifluoromethanesulfonimidate (Li-TFSI, Acros Organics) that was obtained from a $1.8 \mathrm{M}$ stock solution in acetonitrile (Sigma-Aldrich, $99.999 \%$ electronic grade), and $27 \mathrm{mM} \mathrm{FK}$ 209 Co(III) TFSI salt (Dyesol) that was obtained from a 0.27 $\mathrm{M}$ stock solution in acetonitrile. The solution was deposited via spincoating (4000 r/min, $20 \mathrm{~s}, 2000$ (r/min)/s). Method (B): P3HT solution was fabricated from $15 \mathrm{mg} / \mathrm{mL}$ P3HT (Chemborun China), $23 \mathrm{mM}$ 4-tert-butylpyridine, and $0.7 \mathrm{mM} \mathrm{Li}$ TFSI. It was deposited by spincoating $(3000 \mathrm{r} / \mathrm{min}, 30 \mathrm{~s}, 2000$ $(\mathrm{r} / \mathrm{min}) / \mathrm{s})$. Afterward, photoanode contacts covered with perovskite and hole conductor were mechanically cleaned with a scalpel and cotton swabs dipped in acetonitrile. Finally, a 60-nm-thick gold layer as current collector was applied through a stainless steel mask by two different methods: 1) by thermal evaporation on a VaporStation 4 (Oxford Vacuum Science, U.K.), applying a deposition rate of $0.01 \mathrm{~nm} / \mathrm{s}$ for the first $4 \mathrm{~nm}$, followed by $0.1 \mathrm{~nm} / \mathrm{s}$ for the remaining thickness; and 2) by sputtering using a Leica EM ACE200 (Leica Microsystems, Germany) and applying a current of $60 \mathrm{~mA}$ and a deposition duration of $360 \mathrm{~s}$. A mask of adhesive black tape with an active area of $0.2 \mathrm{~cm}^{2}$ was applied on the glass side of the cell prior to photoelectrochemical characterization.

\section{E. Dummy Cell Preparation}

The preparation was analogous to PSC, however, applying merely blocking layer, hole transport layer, and gold layer by thermal evaporation.

\section{F. Characterization}

For photoelectrochemical characterization, a 150-W solar simulator Oriel class A solar simulator, (Newport, USA) using a 1.5 air mass filter (Newport, USA) was employed. The effective irradiation intensity was measured with a single crystal $\mathrm{Si}$ photodiode (Newport, USA). I-V curves were recorded with a potentiostat (Zennium, Zahner-Elektrik GmbH, Germany) at a scan rate of $10 \mathrm{mV} / \mathrm{s}$, sweeping from open-circuit to short-circuit potential (backward scan). Before each measurement, the opencircuit potential $V_{\mathrm{OC}}$ was allowed to stabilize under irradiation, which generally took less than a minute. Care was taken that starting potentials were chosen to be not more than $20 \mathrm{mV}$ superior to $V_{\mathrm{OC}}$ in order to protect the cell [13]. At least three cells of each type were tested for averaged efficiencies. SEM images were recorded with a Quanta 400 FEG (FEI, USA) at the CEMUP materials analysis center of the University of Porto.
FTO on glass is usually employed as transparent conductive substrate, due to its stability toward elevated temperatures. Several sheet resistances are available on the market and generally FTO with a sheet resistance of $7-10 \Omega / \mathrm{sq}$ is chosen, as it is a good compromise in terms of conductivity versus transparency. Thorough substrate cleaning is an essential step and often underrated; however, it plays a pivotal role as the perovskite solar cell is constituted by several layers that are all within the nanometer scale and any contamination of the substrate will thus lead to film defects that lower overall cell efficiency. The scribing of the substrate locally removes the TCO layer and impedes the electric short circuit through the substrate of the photoanode and the cathode. It is often obtained by laser ablation of the conductive layer but not every laboratory possesses a suitable equipment. A low-cost alternative is chemical etching of the conductive layer [14], though it leads to rather inhomogeneous FTO removal. A very versatile and innovative, yet low-cost strategy is the electrochemical reductive treatment of the FTO, which leads to a clean and complete FTO removal on the exposed areas [15].

The compact n-type titanium dioxide film acts as an electronselective layer and thus prevents the recombination of excitons at the TCO surface. If this layer is absent, not dense enough or possesses pinholes, the fabricated cells will show decreased efficiencies due to recombination events. At the same time, it has to be thin enough to provide efficient electron transport by minimizing charge accumulation and therefore recombination. The so-called blocking layer can be fabricated by several ways, including, but not restricting to chemical bath deposition [16], spincoating [4], [17], spray pyrolysis [12], [18], [19], sputtering [20], [21], electron-beam evaporation [22], and atomic layer deposition [23], [24]. We decided to compare $\mathrm{TiO}_{2}$ blocking layers obtained by spray pyrolysis and spincoating of a commercial solution (Ti-Nanoxide BL/SC, Solaronix, Switzerland). An easy means to check if the electrochemical behavior of the blocking layer follows a diode-like behavior is to fabricate dummy cells. Such cells are composed of the compact $\mathrm{TiO}_{2}$ layer on top of the TCO substrate, a hole-transport layer like spiro-OMeTAD and a gold contact, thus similar to a perovskite cell, however without any photoactive layer. Cyclic voltammetry (CV) has been performed on dummy cells with different BL and the results are shown in Fig. 2(a). In the case of a BL made by spray pyrolysis, the CV shows zero anodic current and a steep increase of the cathodic current which suggests a dense and pinhole-free layer with high electronic conductivity. In case of the BL formed by spin coating, the $\mathrm{CV}$ shows, in addition to the cathodic current increase at lower potential, a sluggish cathodic and anodic current evolution across the entire potential window, which is an indication for pinholes. For comparison, the CV of a dummy cell without any blocking layer demonstrates a typical ohmic behavior, proving the absence of any blocking effect at positive potential. The PSC corresponding to the BL fabrication methods show $I-V$ curves that underline the extremely important role of the blocking layer. The cell with the BL made by spray pyrolysis shows best efficiencies, whereas that made with spincoated blocking layer performs worse. The cell without any BL shows 


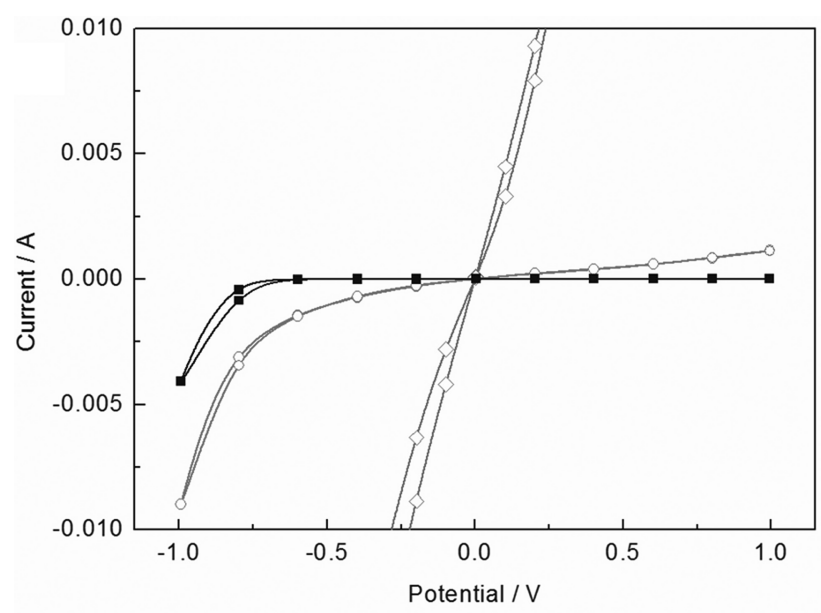

(a)

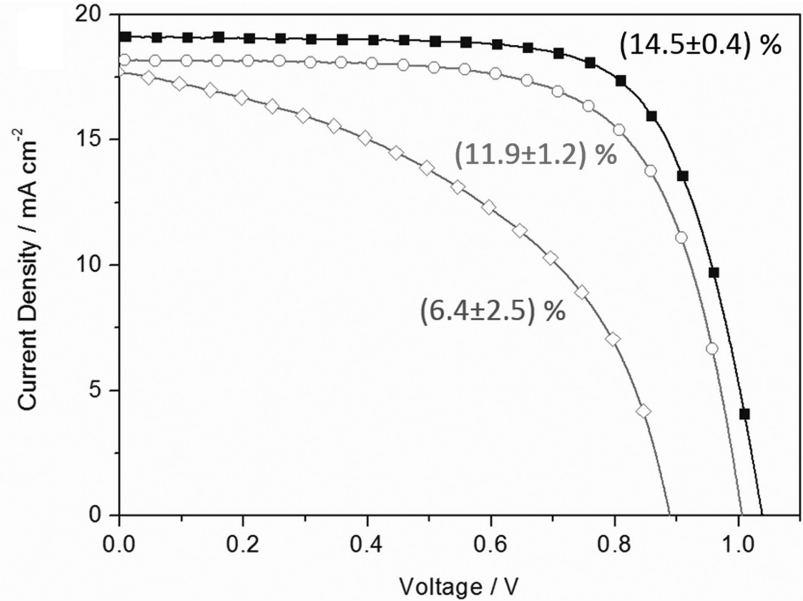

(b)

Fig. 2. (a) CV of dummy cells without blocking layer (grey diamonds), blocking layer made by spincoating (red circles) and by spray pyrolysis (black squares). (b) $I-V$ curves of PSC with a blocking layer made by spray pyrolysis (black squares), spincoating of a commercial solution (red circles) and without any blocking layer (grey diamonds) at 0.95 sun.
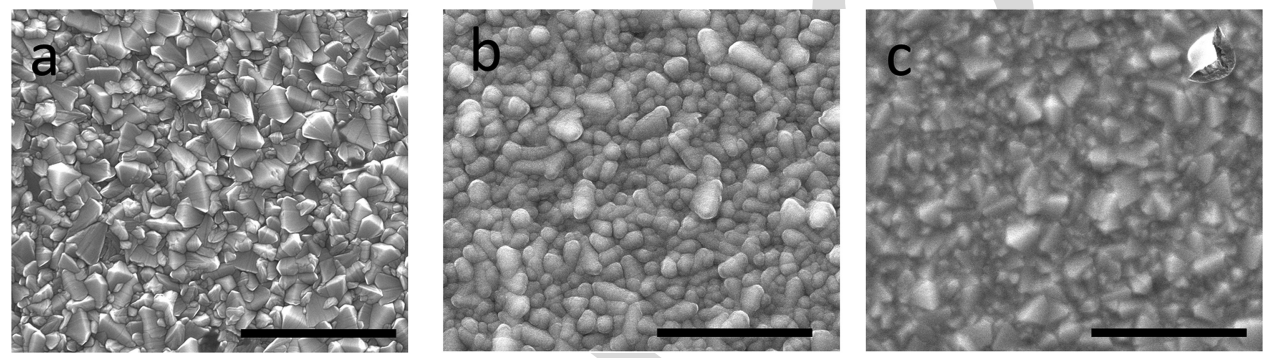

Fig. 3. (a) Scanning electron microscopy images (top-view) of a bare $\mathrm{TCO}$ substrate. (b) $\mathrm{TiO}_{2}$ compact layer deposited by spray pyrolysis. (c) Spincoating of a commercial solution. Black bars correspond to $2 \mu \mathrm{m}$.

TABLE I

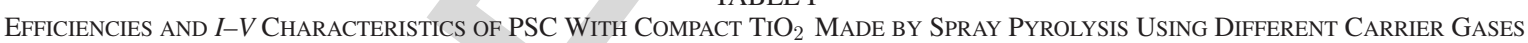

\begin{tabular}{ccccc}
\hline Spray pyrolysis carrier gas & $J_{\mathrm{sc}} / \mathrm{mA} \mathrm{cm}^{-2}$ & $V_{\mathrm{oc}} / \mathbf{V}$ & $\mathrm{FF}$ & $\eta / \%$ \\
\hline Air (best cell) & 18.6 & 1.09 & 0.76 & 15.8 \\
\hline Air (average) & & & & $15.5 \pm 0.4$ \\
\hline $\mathbf{O}_{2}$ (best cell) & 19.0 & 0.98 & 0.77 & 14.8 \\
\hline $\mathbf{O}_{2}$ (average) & & & & $14.0 \pm 0.7$ \\
\hline
\end{tabular}

the lowest efficiencies that, however, are not zero. The reason is that the perovskite layer itself is an electron transporter [17] as well as it is capable to transport holes [25], [26]. This renders the TCO-perovskite interface into a nonselective contact that promotes recombination and therefore leads to decreased efficiencies.

Images of the different blocking layers recorded by scanning electron microscopy show some fundamental differences, see Fig. 3. The layer deposited by spray pyrolysis is rather thin and homogeneous, whereas the layer deposited by spin coating is thicker and shows cracks, see Fig. 3(c) (upper right corner). It can be concluded that PSC with a BL fabricated by spray pyrolysis show superior efficiencies and therefore, this fabrication method might be recommended. The influence of the carrier gas on cell efficiencies was further tested but it came out that pure oxygen did not improve cell efficiencies, see Table I. Due to 278 lack of deposition control, BL thickness may vary between $30 \quad 279$ and $80 \mathrm{~nm}$, as occasional SEM cross sections showed. However, 280 no correlated impact on PSC efficiency could be stated. 281

Mesoporous titania layer has been employed in dye-sensitized 282 solar cells (DSSC), with the function to increase the active sur- 283 face area and transport electrons under light excitation [27]. As 284 the initial perovskite solar cells were thought as a continuity of 285 DSSC, a mesoporous titania film also was applied here, even if 286 the extinction coefficient of perovskites such as $\left(\mathrm{CH}_{3} \mathrm{NH}_{3}\right) \mathrm{PbI}_{3} \quad 287$ is about ten times higher than that of N719 dye [28]. As 288 a consequence, the necessity of active surface increase is 289 turned obsolete. Thus, PSC without mesoporous layer, so-called 290 planar devices, have been developed, though their efficiencies 291 were lagging behind those employing a mesoporous layer for 292 


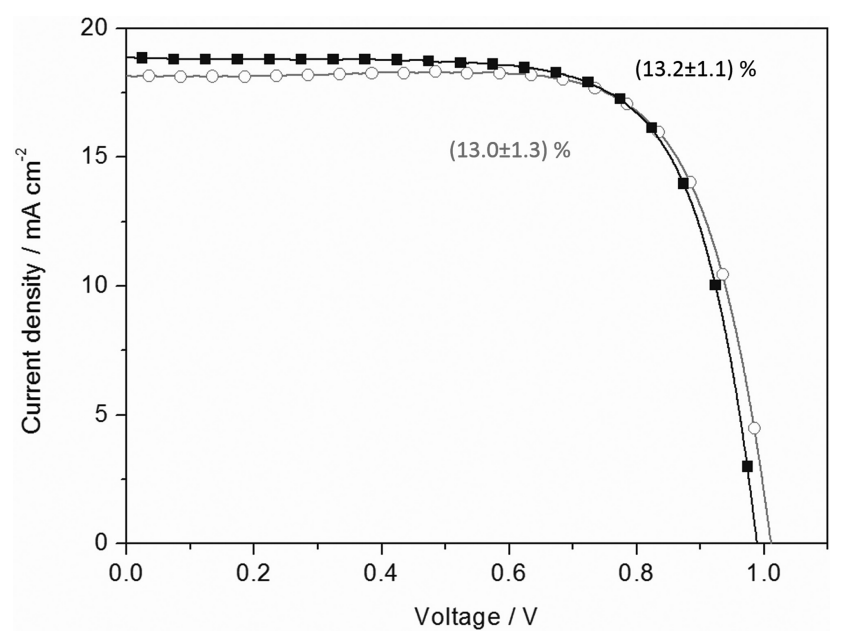

Fig. 4. $\quad I-V$ curve of cells with a mesoporous $\mathrm{TiO} 2$ layer made from $30 \mathrm{NR}$ $\mathrm{D}$ paste (average particle size of $30 \mathrm{~nm}$, black squares) and from 18-NR-T paste (average particle size of $20 \mathrm{~nm}$, red circles) at 0.94 sun. Both pastes were purchased from Dyesol Ltd.

a long time [7]. Only recently, the efficiency gap has become rather small, which is due to improved interface engineering [7], [18], [29]. Beside higher efficiencies, PSC with a mesoporous layer show reduced efficiency deviation between forward and backward scan, a phenomenon described as hysteresis [19], [30], [31]. When Snaith et al. demonstrated that even with mesoporous layers of alumina, a material that cannot participate in electron transfer due to band energy mismatch, high efficiencies of $15.9 \%$ could be obtained [32], it was deduced that the mesoporous layer mainly fulfills a structural role for crystal growth and geometry determination, even if efficient electron injection from the perovskite into the $\mathrm{TiO}_{2}$ mesoporous layer was reported [33]. However, latest results demonstrate that ionic migration at the perovskite/ $\mathrm{TiO}_{2}$ interface, which is responsible for charge accumulation and therefore recombination events, is reduced or even suppressed in the presence of the $\mathrm{TiO}_{2}$ mesoporous layer [34]. As hysteresis also depends on ionic migration [35]-[38], its reduction in the presence of mesoporous $\mathrm{TiO}_{2}$ is the consequence. Putting all together, best results have been achieved so far using a thin $\mathrm{TiO}_{2}$ mesoporous layer and a perovskite capping layer that prevents recombination between $\mathrm{TiO}_{2}$ and the hole transport layer [33], [34].

There exist several commercial pastes with different sizes of $\mathrm{TiO}_{2}$ particles and therefore, it was decided to compare two different particle sizes, namely one possessing $20 \mathrm{~nm}$ and one with $30 \mathrm{~nm}$ average particle diameter. The same paste dilution ratio in pure ethanol (1:6) as well as the same deposition and sintering conditions were applied. Fig. 4 shows that both mesoporous layers lead to very comparable cell efficiencies that are within the error scale. This points toward a higher tolerance and toward a mesoporous layer architecture, as long as the particle size remains similar.

Within perovskite materials, there exists a huge variety of recipes and deposition techniques, which are well summarized in the book by Park et al. [10] and in the review by Song et al. [39]. It might be not an easy task to decide for the suitable perovskite type and fabrication process. The name perovskite refers to a crystalline structure of the type $\mathrm{ABX}_{3}, \mathrm{~A}$ and $\mathrm{B}$ be- ing cations and $\mathrm{X}$ an anion. The perovskite class suitable for solar cells is an organic lead halide, with A being generally an organic cation, B being the lead ion, and $\mathrm{X}$ being a halogen, usually bromine, iodide, chlorine, and mixtures thereof. Lead substitution by tin and germanium analogs leads to perovskites with severe stability problems [32], [40], [41] and therefore will not be addressed here. Our focus was to determine a perovskite formulation easy to implement and that results in reproducible perovskite layers with enhanced stability. Many results have been published with monocationic perovskites, however, with some inherent limitations that are briefly exposed here: $\mathrm{MAPbI}_{3}$ has been intensively studied [42] but has some drawbacks such as weak stability toward moisture [43], [44] and temperature [45]. Formamidinium (FA) was proposed as alternative cation; however, its perovskite analog $\mathrm{FAPbI}_{3}$ crystallizes in the photoinactive phase below $60{ }^{\circ} \mathrm{C}$ [46], such as the inorganic cation analog $\mathrm{CsPbI}_{3}$ [47]. Whereas several groups observed improved stability of the photoactive phase upon using binary mixed cation perovskites [48]-[52], Saliba et al. decided to combine the three cations in a perovskite and achieved high efficiencies $(>20 \%)$ on a very reproducible basis [12].

Several methods exist for solution-processed film fabrication, the most common being simple spreading of the perovskite precursor solution on the substrate, also known as one-step deposition. However, films with poor surface control and therefore huge efficiency variations generally emerge [42]. A more sophisticated approach is the sequential step deposition, where the metal halide is first deposited and annealed before being brought in contact with the ammonium salt as vapor or in solution [42], [53]. Nevertheless, several drawbacks of this deposition method were experienced in our group, such as incomplete conversion of the metal halide or partial dissolution of the perovskite during the subsequent washing step. Furthermore, it is more time-consuming as it requires two sintering steps. The antisolvent technique was introduced in 2014 by the group of Seok [19] and since then, it has been the method of choice for subsequently published record efficiencies [7]. It is quite simple to implement and requires only one precursor solution, whereas the crystallization of the perovskite is initiated by adding a socalled antisolvent. This antisolvent is chosen not to dissolve the perovskite on one side and to displace the solvent of the latter on the other side. The main drawback of this deposition method is its artisanal aspect, requiring a certain degree of training before reaching enhanced reproducibility. However, smooth perovskite films with homogeneous composition and large grain boundaries are obtained after a short training time. Fig. 5(a) shows a cross section of a PSC with the monolithic perovskite capping layer on top of the mesoporous $\mathrm{TiO}_{2}$ layer with grains growing from the bottom to the top and which are thought to enhance charge transport, according to Saliba et al. [12]. The top view of the perovskite layer [see Fig. 5(b)] shows grains possessing diameters between 200 and $500 \mathrm{~nm}$, which is in good agreement with the original report [12].

One of the biggest detrimental factors for perovskite fabrication and stability is atmospheric humidity, together with oxygen [54]. PSC that are meant to exhibit prolonged stability require fabrication and storage in inert atmosphere or device encapsulation after fabrication [55], [56]. Therefore, PSC are 
TABLE II

Best and AVERage EfFiciencies for PSC, While the Perovskite LaYer Was Fabricated Within DifFEREnt Conditions

\begin{tabular}{|c|c|c|c|c|}
\hline Perovskite fabrication condition & $J_{s c} / \mathrm{mA} \mathrm{cm}^{-2}$ & $V_{o c} / \mathrm{V}$ & $F F$ & $\eta / \%$ \\
\hline \multirow[t]{2}{*}{$0 \%$ rel. humidity, $25^{\circ} \mathrm{C}$} & 18.46 & 1.06 & 0.72 & 15.1 (best) \\
\hline & & & & $14.7 \pm 0.3$ (average) \\
\hline \multirow[t]{2}{*}{$58 \%$ rel. humidity, $25^{\circ} \mathrm{C}$} & 16.26 & 0.83 & 0.67 & 9.9 (best) \\
\hline & & & & $7.4 \pm 2.4$ (average) \\
\hline \multirow[t]{2}{*}{$58 \%$ rel. humidity, $100^{\circ} \mathrm{C}$} & 17.59 & 1.02 & 0.57 & 10.8 (best) \\
\hline & & & & $7.4 \pm 2.6$ (average) \\
\hline
\end{tabular}
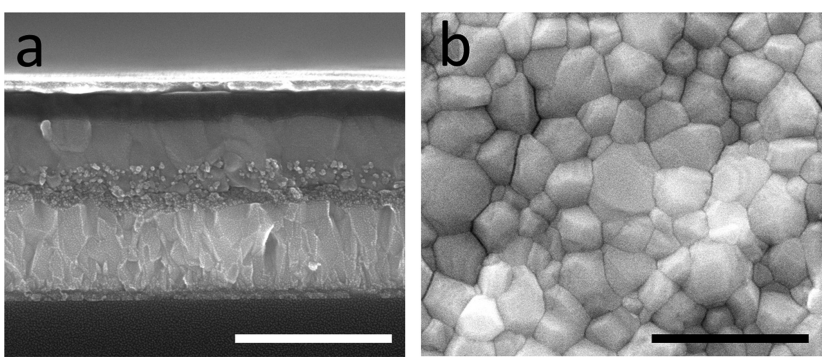

Fig. 5. SEM images. (a) Cross section of the entire PSC device showing the compact $\mathrm{TiO}_{2}$ layer (ca. $80 \mathrm{~nm}$ ), followed by the mesoporous layer of 150 $200 \mathrm{~nm}$. The adjacent perovskite layer partially infiltrates into the mesoporous structure and its capping layer has a thickness of 200-300 nm. The spiroMeOTAD hole transport layer (dark grey) has a thickness of 130-190 nm, followed by a 60-nm-thick gold layer as current collector (light grey). (b) Top view of the perovskite layer, showing grains with ca. $200-500 \mathrm{~nm}$ diameter. The fissures evolved during image capture and therefore are believed to be due to imaging. Bars correspond to $1 \mu \mathrm{m}$. generally fabricated in glove boxes with dry and oxygen-free atmosphere. And not only that, also the substrates should be absolutely moisture-free. After sintering the mesoporous layer, substrates should thus be handled only in dry atmosphere or transferred to dry atmosphere such as a glove box before cooling below $150^{\circ} \mathrm{C}$. Within the degradation mechanism of perovskite structures, oxygen only interferes subsequently to hydratation [56] and can therefore be considered less critical if moisture is absent or very low. Laboratories that are newcomers in this area of research might not possess a glove box infrastructure. Low atmospheric humidity levels are assumed to be less critical to perovskite fabrication but these conditions depend strongly on the geographic localization, the season, and some more inherent factors. To demonstrate the effect of moisture and oxygen atmosphere on perovskite formation, a comparative test of PSC devices that were fabricated inside and outside the glove box (relative humidity outside the glove box: 58\%) was performed. The results are displayed in Fig. 6 and Table II and it can be observed that in case of perovskite being fabricated in ambient atmosphere, the active layer showed a lighter color and the corresponding PSC showed a both lower $V_{\mathrm{OC}}$ and $J_{\mathrm{SC}}$, whereas the fill factor remained rather uninfluenced. As a strategy to minimize water uptake by the substrate, samples were heated to $100{ }^{\circ} \mathrm{C}$ immediately before the perovskite precursor solution was deposited. Corresponding PSC showed an improved $V_{\mathrm{OC}}$ and $J_{\mathrm{SC}}$, however the fill factor decreased. This is likely due to inhomogeneous crystal growth, induced by the elevated temperature of the substrate. For the best cells obtained, a lit-

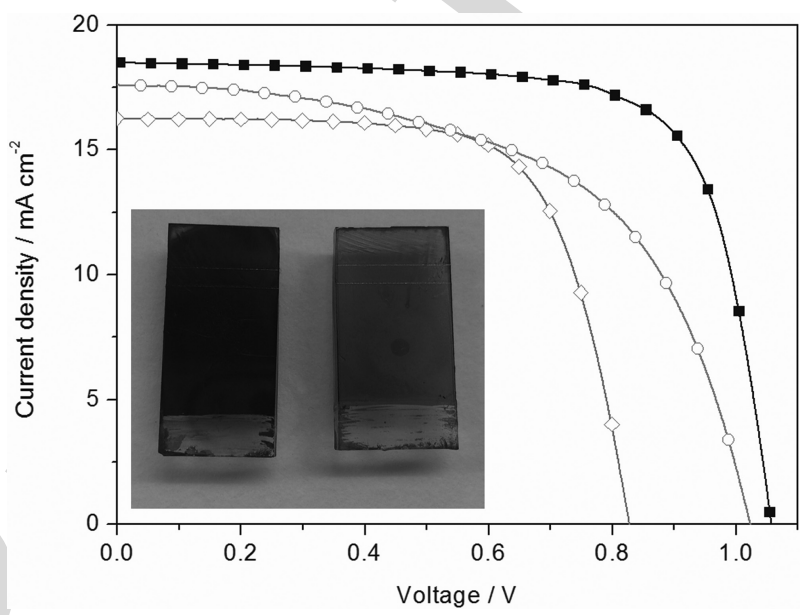

Fig. 6. $I-V$ curves of PSC fabricated in a glove box with $0 \%$ relative humidity at $25{ }^{\circ} \mathrm{C}$ (black squares), at ambient humidity $\left(58 \%\right.$ relative humidity) at $25^{\circ} \mathrm{C}$ (grey diamonds), and at ambient humidity with substrate preheating at $100{ }^{\circ} \mathrm{C}$ (red circles) with an incident light intensity of 0.94 sun. Image: Sample with perovskite produced inside (left) and outside the glove box (right) at $25^{\circ} \mathrm{C}$.

tle improvement can be stated when hot substrates were used, though average efficiencies came out to be very similar to those without heat treatment.

This study shows that it is highly recommended to work with a glove box, providing very low humidity $(<0.002 \%$ rel. humidity) and oxygen levels. Another possible strategy might be the use of a perovskite formulation that is optimized toward enhanced resistance at elevated humidity levels [57].

Atop the photoactive layer, the hole conducting layer selectively transports the holes to the current collector and therefore fulfills the complementary role to the $\mathrm{TiO}_{2}$ layer. It has to be pinhole-free to inhibit contact of the current collector with the perovskite layer, for the same reasons that were already stressed out concerning the electron conducting layer. Generally, a formulation using spiro-OMeTAD is used that contains, among others, the ionic liquid LiTFSI to increase hole conductivity. However, both LiTFSI and spiro-OMeTAD have hydrophilic properties and promote humidity ingestion, leading to poor humidity stability of the entire device. At temperatures above $55^{\circ} \mathrm{C}$, the molecular hole transporter crystallizes, which severely affects cell efficiencies. Two different hole conductor layers were compared toward their stability, namely spiro-oMeTAD as molecular HTL and poly(3-hexylthiophene) (P3HT) as polymeric HTL. 


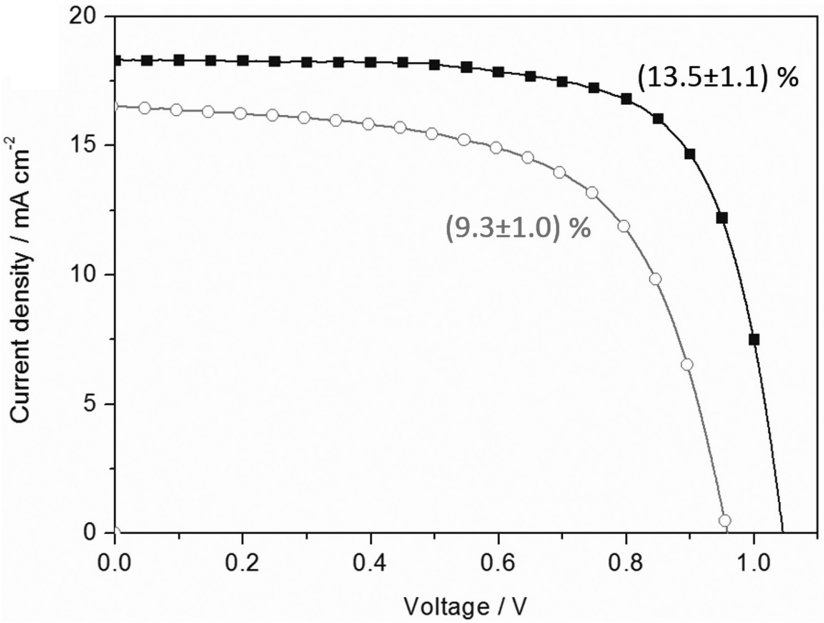

(a)

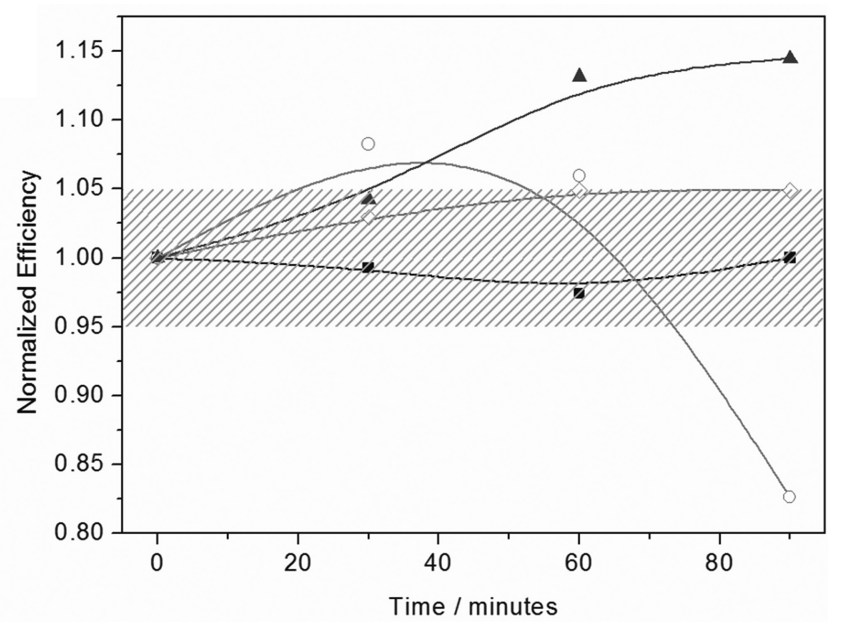

(b)

Fig. 7. (a) $I-V$ curves of PSC employing spiro-OMeTAD (black squares) and P3HT (red circles) as HTL at 0.95 sun. (b) Normalized efficiency stability of PSC using two PSC with spiro-OMeTAD (black squares and grey diamonds) and two with P3HT (red circles and blue triangles). The hatched green area indicates a deviation less than $5 \%$ from the initial efficiency.

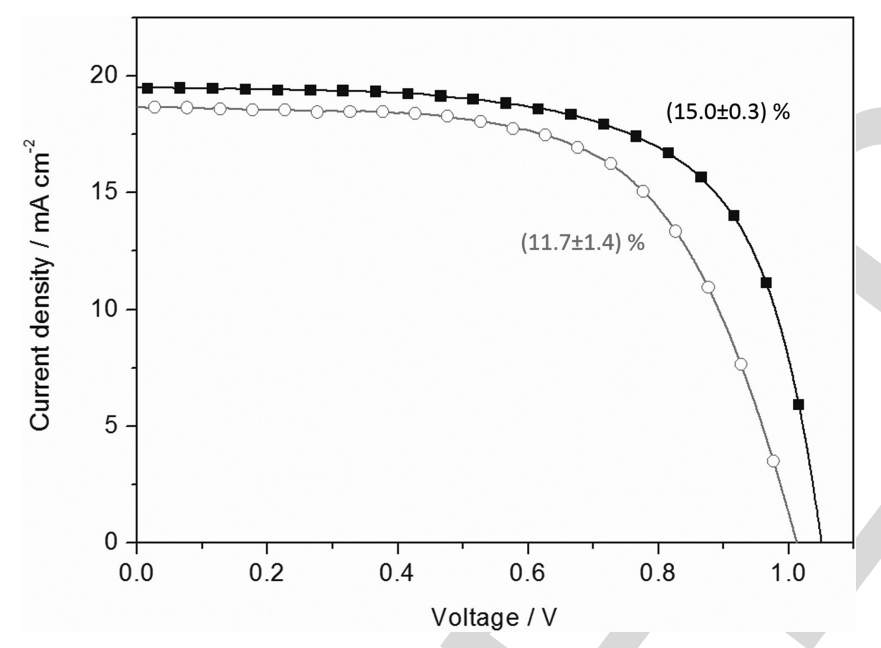

Fig. 8. $I-V$ curves of PSC possessing a gold current collector made by thermal evaporation (black line) and by sputtering (red line) at 0.93 sun.
It turns out that spiro-OMeTAD leads to better efficiencies, see Fig. 7(a), showing better current density, open-circuit potential, and fill factor altogether. A potential advantage could lie in an enhanced stability despite lower efficiency when P3HT is employed, but the experimental data could not confirm this assumption, see Fig. 7(b), within the limited time frame.

Generally, current collectors are made of gold despite its higher cost, as alternative metals such as $\mathrm{Ag}$ and $\mathrm{Al}$ have been demonstrating weak stabilities [58]-[60]. Among gold deposition methods, one of the most common ones are sputtering and thermal evaporation. However, almost all published works use thermal evaporation. We decided therefore to compare gold films with similar thickness that were fabricated by these two techniques. Indeed, thermal evaporation leads to a better overall cell performance, see Fig. 8.

The reason for the worse performance of PSC with sputtered current collector was evidenced by doing a scotch test. While in case of thermal evaporation, the gold layer could be easily 457 stripped off, in case of sputtering deposition, the gold remained 458 stuck into HTM. Even after dissolving the HTM layer, gold 459 traces were still detected with the naked eye inside the per- 460 ovskite layer. This means that during the gold layer deposition, 461 surface bombardment provokes penetration of gold deep into 462 the device structure, creating recombination centers. Thus, a 463 thermal evaporator is needed for efficient perovskite solar cell 464 fabrication, even if this step considerably increases the energy 465 payback time of PSC [61].

Following all the layer fabrication steps mentioned before, it was possible to fabricate PSC with an average efficiency of $(14.8 \pm 1.0) \%$ for a set of 49 cells, see Fig. 9 left.

In laboratory conditions, cell efficiencies are generally measured for cell active areas inferior to $1 \mathrm{~cm}^{2}$. The cell area delimited by the deposition of the current collector should be only slightly superior to the active cell area (delimited by a mask) to avoid recombination events. Instead of using crocodile clamps arbitrarily connected to the cell, a suitable sample holder is preferable, see Fig. 9 right, for maximal reproducibility. Among all factors that describe the cell's performance, the maximum power point (MPP) is the most valuable information in terms of applicability in solar devices as it describes best the operating parameters of the cell [7], [13], [62]. The MPP is obtained via mathematic extraction from $I-V$ curves and surprisingly has not yet gained big attention in published scientific works. $I-V$ curves are generally obtained by dynamic scanning of external loads though care must be taken that the scan rate does not overpass the dynamic electrochemical events inside the perovskite cell. An example is given in Fig. 10, where a PSC was measured at several scan rates. If merely the $I-V$ curve is considered for efficiency determination, best results are obtained with a scan rate of $1 \mathrm{~V} / \mathrm{s}$. But if $\mathrm{CV}$ of the same cell are recorded at $10 \mathrm{mV} / \mathrm{s}$ and at $1 \mathrm{~V} / \mathrm{s}$, a striking difference is observed concerning the hysteresis, see Fig. 11. Whereas hysteresis is rather low in the former case, it considerably increases in the latter case. This 

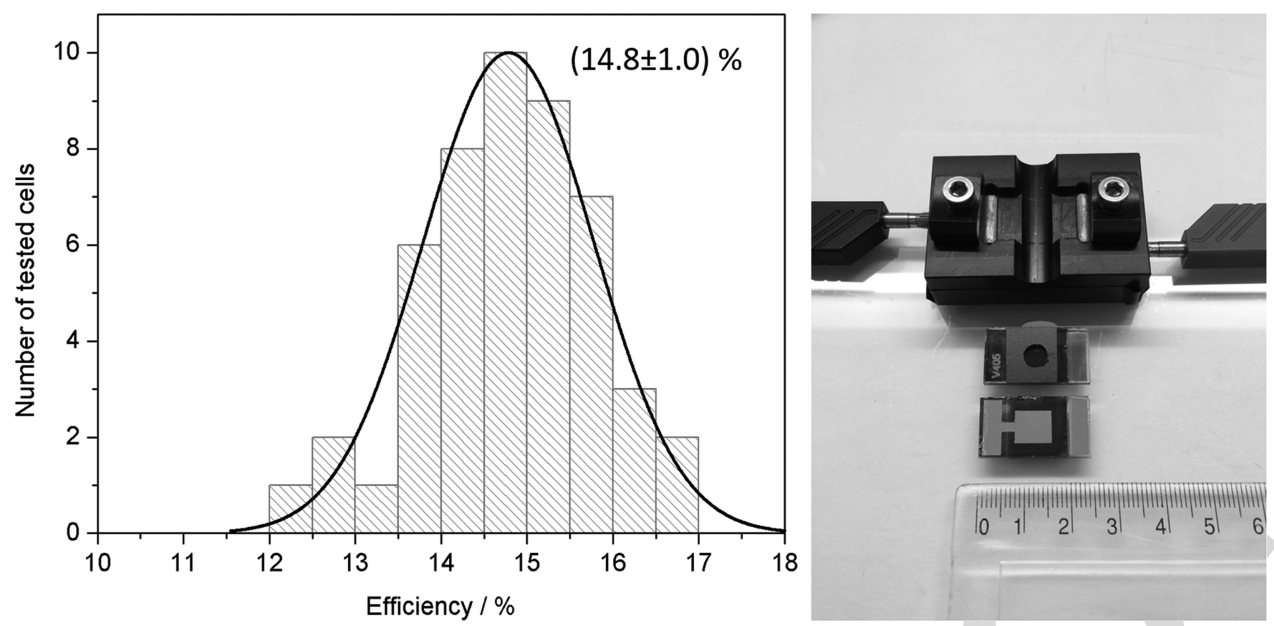

Fig. 9. Efficiency distribution of all cells fabricated in standard conditions (left) and cell architecture with testing device for reproducible testing conditions (right).

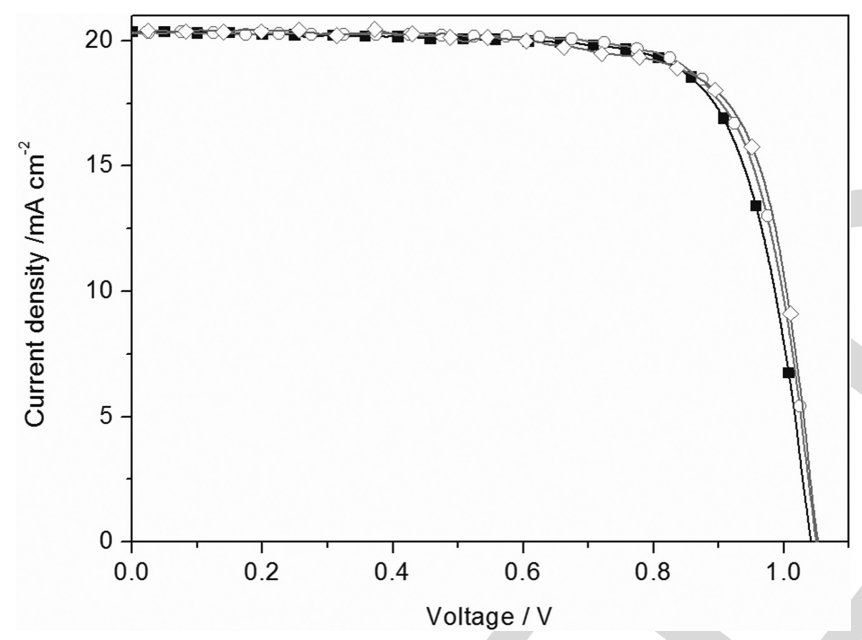

Fig. 10. $\quad I-V$ curves and efficiencies of a PSC recorded at different scan rates at 0.98 sun: $10 \mathrm{mV} / \mathrm{s}$ (black squares), $100 \mathrm{mV} / \mathrm{s}$ (red circles), $1 \mathrm{~V} / \mathrm{s}$ (grey diamonds).

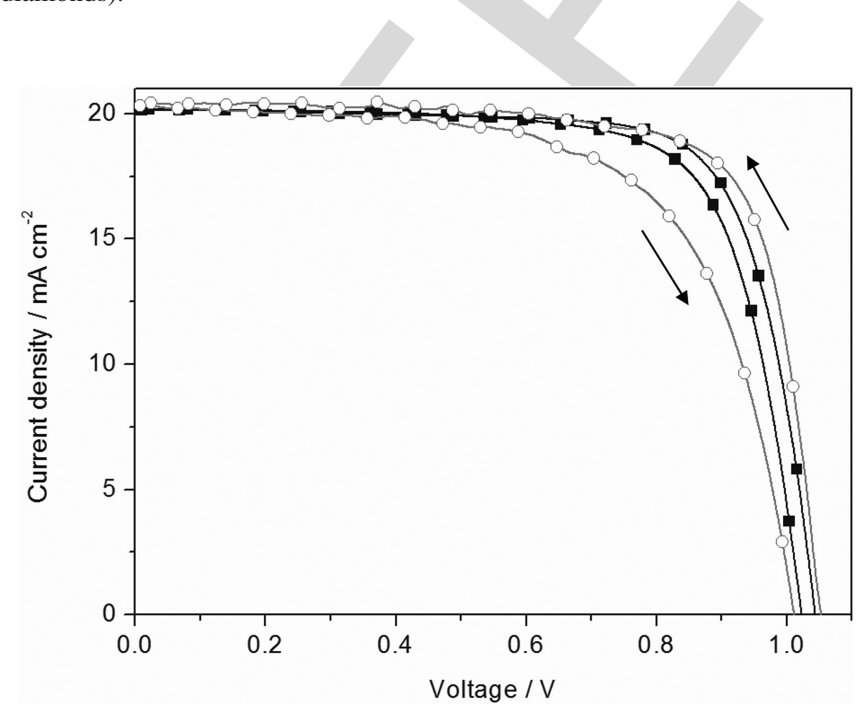

Fig. 11. Hysteresis of a PSC recorded at a scan rate of $10 \mathrm{mV} / \mathrm{s}$ (black squares) and $1 \mathrm{~V} / \mathrm{s}$ (red circles) at 0.98 sun. means that if the $I-V$ curve is recorded in backward scan in such 493 conditions, the obtained results do not reflect the cell's real be- 494 havior and therefore lead to overestimation of cell performance 495 [7], [13]. Lacking so far easily implementable measurement 496 protocols for MPP tracking, conditions for $I-V$ curve recording 497 should be carefully chosen, with the goal to not overestimate 498 real cell characteristics.

\section{CONCLUSION}

PSC represent a very attractive photovoltaic technology, as 501 innumerous publications have demonstrated, however initiating 502 in this area may be a hard task. PSC are made of several thin 503 layers and not only each layer, but also each interface plays 504 an important role for the manufacturing of efficient devices. 505 This paper is mainly directed toward research groups and sci- 506 entists that are beginners in this active field of research and as 507 such, it was intended to point out fabrication details that remain 508 barely discussed in most publications, but that are significant 509 for the preparation of efficient cells. It was evidenced that be- 510 sides the usual equipment for thin-film preparation (hot plate, 511 spin coater, programmable furnace, etc.) and photoelectrochem- 512 ical characterization (potentiostat or variable external load, solar 513 simulator), a glove box and a thermal evaporator for the depo- 514 sition of the gold current collector are strongly advised. The 515 goal of this paper is to analyze and optimize each layer and, as 516 a consequence, demonstrate their influence on the entire PSC 517 device.

It was evidenced by experiments that for PSC performing 519 best, blocking layer has to be fabricated via spray pyrolysis, 520 whereas comparable results were obtained when pure oxygen or 521 air was used as carrier gas. For the mesoporous layer, no differ- 522 ence could be stated for both particle sizes used $(20$ and $30 \mathrm{~nm}) ; \quad 523$ however, it is likely that a bigger difference in size may be of 524 matter. Our experience showed that best results for perovskite 525 films were obtained by applying the antisolvent technique with 526 a triple cation formulation. It was demonstrated that concerning 527 the adjacent hole transport layer, spiro-OMeTAD was resulting 528 
in cells with superior efficiency compared with the polymeric analog P3HT. Finally, two techniques for the fabrication of gold current collector were presented and it was demonstrated that thermal evaporation leads to better PSC than sputtering, as in case of the latter the energetic surface bombardment provoked gold particle penetration until the perovskite active layer, thus creating recombination centers. Incorporating all the discussed optimizations, PSC with an average efficiency of $(14.8 \pm 1.0) \%$ were fabricated. Furthermore, an innovative, versatile, and quick method for electrochemical substrate etching was applied in PSC, making laser-assisted scribing and therefore the necessity of such an equipment obsolete. Dummy cells as selective electrochemical characterization method for single layers were introduced and yielded versatile results for the qualitative comparison of $\mathrm{TiO}_{2}$ blocking layers. It is believed that this paper contributes to a faster implementation of PSC fabrication in research groups with few experience in this area, thanks to a deeper understanding of fabrication details and useful analysis tools that are easily available.

\section{ACKNOWLEDGMENT}

The authors would like to thank M. Grätzel for hosting I. Mesquita at EPFL to deepen the knowledge about PSC fabrication and O. Bellon from Greatcellsolar Ltd. for fruitful discussions.

\section{REFERENCES}

[1] U.S.E.I. Administration, Washington, DC, USA, Annual Energy Outlook, 2017.

[2] I.I.R.E. Agency, Abu Dhabi, UAE, REthinking Energy 2017: Accelerating the global energy transformation, 2017.

[3] I.I.R.E. Agency, Abu Dhabi, UAE, Renewable Energy and Jobs Annual Review, 2016.

[4] H.-S. Kim et al., "Lead iodide perovskite sensitized all-solid-state submicron thin film mesoscopic solar cell with efficiency exceeding 9\%," Sci. Rep., vol. 2, 2012, Art. no. 591

[5] NREL efficiency chart. [Online.] Available: https://www.nrel.gov/pv/ assets/images/efficiency-chart.png. Accessed on: Mar. 26, 2018.

[6] [Online.] Available: http://www.greatcellsolar.com/wp-content/uploads/ 2018/03/Aurora-Newsletter-March-2018-Final-ENG-RC.pdf

[7] J.-P. Correa-Baena et al., "The rapid evolution of highly efficient perovskite solar cells," Energy Environ. Sci., vol. 10, pp. 710-727, 2017.

[8] T. Salim, S. Sun, Y. Abe, A. Krishna, A. C. Grimsdale, and Y. M. Lam, "Perovskite-based solar cells: Impact of morphology and device architecture on device performance," J. Mater. Chem. A, vol. 3 pp. 8943-8969, 2015.

[9] I. Mesquita, L. Andrade, and A. Mendes, "Perovskite solar cells: Materials, configurations and stability," Renewable Sustain. Energy Rev., vol. 82, pp. 2471-2489, 2018.

[10] N. G. Park, M. Grätzel, and T. Miyasaka, Organic-Inorganic Halide Perovskite Photovoltaics: From Fundamentals to Device Architectures. New York, NY, USA: Springer, 2016.

[11] C. C. Wu, C. I. Wu, J. C. Sturm, and A. Kahn, "Surface modification of indium tin oxide by plasma treatment: An effective method to improve the efficiency, brightness, and reliability of organic light emitting devices," Appl. Phys. Lett., vol. 70, pp. 1348-1350, 1997.

[12] M. Saliba et al., "Cesium-containing triple cation perovskite solar cells: Improved stability, reproducibility and high efficiency," Energy Environ. Sci., vol. 9, pp. 1989-1997, 2016.

[13] J. A. Christians, J. S. Manser, and P. V. Kamat, "Best practices in perovskite solar cell efficiency measurements. Avoiding the error of making bad cells look good," J. Phys. Chem. Lett., vol. 6, , pp. 852-857, 2015.

[14] H.-R. Xia, J. Li, W.-T. Sun, and L.-M. Peng, "Organohalide lead perovskite based photodetectors with much enhanced performance," Chem. Commun., vol. 50, pp. 13695-13697, 2014.
[15] S. P. Koiry et al., "An electrochemical method for fast and controlled etching of fluorine-doped tin oxide coated glass substrates," J. Electrochem. Soc., vol. 164, pp. E1-E4, 2017.

[16] G. Yin et al., "Enhancing efficiency and stability of perovskite solar cells through $\mathrm{Nb}$-doping of $\mathrm{TiO} 2$ at low temperature," ACS Appl. Mater Interfaces, vol. 9, pp. 10752-10758, 2017.

[17] M. Liu, M. B. Johnston, and H. J. Snaith, "Efficient planar heterojunction perovskite solar cells by vapour deposition," Nature, 501, pp. 395-398, 2013.

[18] D. Bi et al., "Polymer-templated nucleation and crystal growth of perovskite films for solar cells with efficiency greater than $21 \%$," Nature Energy, vol. 1, 2016, Art. no. 16142.

[19] N. J. Jeon, J. H. Noh, Y. C. Kim, W. S. Yang, S. Ryu, and S. I. Seok, "Solvent engineering for high-performance inorganic-organic hybrid perovskite solar cells," Nature Mater, vol. 13, pp. 897-903, 2014.

[20] D. Yang, Z. Yang, W. Qin, Y. Zhang, S. Liu, and C. Li, "Alternating precursor layer deposition for highly stable perovskite films towards efficient solar cells using vacuum deposition," J. Mater. Chem. A, vol. 3, pp. 9401-9405, 2015.

[21] D. Yang et al., "Surface optimization to eliminate hysteresis for record efficiency planar perovskite solar cells," Energy Environ. Sci., vol. 9, pp. 3071-3078, 2016.

[22] K. Wang et al., "CO2 Plasma-treated $\mathrm{TiO} 2$ film as an effective electron transport layer for high-performance planar perovskite solar cells," ACS Appl. Mater. Interfaces, vol. 9, pp. 33989-33996, 2017.

[23] W. Yongzhen et al.,"Highly compact TiO 2 layer for efficient holeblocking in perovskite solar cells," Appl. Phys. Express, vol. 7, 2014, Art. no. 052301.

[24] $\mathrm{H}$. Hu et al., "Atomic layer deposition of $\mathrm{TiO} 2$ for a high-efficiency holeblocking layer in hole-conductor-free perovskite solar cells processed in ambient air," ACS Appl. Mater. Interfaces, vol. 8, pp. 17999-18007, 2016

[25] L. Etgar, Hole Transport Material (HTM) Free Perovskite Solar Cell, Hole Conductor Free Perovskite-Based Solar Cells. Cham, Switzerland: Springer, 2016, pp. 9-24.

[26] L. Etgar et al., "Mesoscopic $\mathrm{CH} 3 \mathrm{NH} 3 \mathrm{PbI} 3 / \mathrm{TiO} 2$ heterojunction solar cells," J. Amer. Chem. Soc., vol. 134, pp. 17396-17399, 2012.

[27] A. Hagfeldt, G. Boschloo, L. Sun, L. Kloo, and H. Pettersson, "Dyesensitized solar cells," Chem. Rev., vol. 110, pp. 6595-6663, 2010.

[28] J.-H. Im, C.-R. Lee, J.-W. Lee, S.-W. Park, and N.-G. Park, "6.5\% efficient perovskite quantum-dot-sensitized solar cell," Nanoscale, vol. 3 pp. 4088-4093, 2011.

[29] E. H. Anaraki et al., "Highly efficient and stable planar perovskite solar cells by solution-processed tin oxide," Energy Environ. Sci., vol. 9, pp. 3128-3134, 2016.

[30] H. J. Snaith et al., "Anomalous hysteresis in perovskite solar cells," $J$. Phys. Chem. Lett., vol. 5, pp. 1511-1515, 2014.

[31] B. Chen, M. Yang, S. Priya, and K. Zhu, "Origin of J-V hysteresis in perovskite solar cells," J. Phys. Chem. Lett., vol. 7, pp. 905-917, 2016.

[32] K. Wojciechowski, M. Saliba, T. Leijtens, A. Abate, and H. J. Snaith, "Sub150 [degree]C processed meso-superstructured perovskite solar cells with enhanced efficiency," Energy Environ. Sci., vol. 7, pp. 1142-1147, 2014.

[33] T. Leijtens, B. Lauber, G. E. Eperon, S. D. Stranks, and H. J. Snaith, "The importance of perovskite pore filling in organometal mixed halide sensitized TiO2-based solar cells," J. Phys. Chem. Lett., vol. 5, pp. 10961102, 2014.

[34] M. Anaya et al., "Electron injection and scaffold effects in perovskite solar cells," J. Mater. Chem. C, vol. 5, pp. 634-644, 2017.

[35] E. L. Unger et al., "Hysteresis and transient behavior in current-voltage measurements of hybrid-perovskite absorber solar cells," Energy Environ. Sci., vol. 7 pp. 3690-3698, 2014.

[36] W. Tress, N. Marinova, T. Moehl, S. M. Zakeeruddin, M. K. Nazeeruddin, and M. Gratzel, "Understanding the rate-dependent J-V hysteresis, slow time component, and aging in $\mathrm{CH} 3 \mathrm{NH} 3 \mathrm{PbI} 3$ perovskite solar cells: The role of a compensated electric field," Energy Environ. Sci., vol. 8, pp. 995$1004,2015$.

[37] S. Meloni et al., "Ionic polarization-induced current-voltage hysteresis in CH3NH3PbX3 perovskite solar cells," Nature Commun., vol. 7, 2016, Art. no. 10334.

[38] G. Richardson et al., "Can slow-moving ions explain hysteresis in the current-voltage curves of perovskite solar cells?" Energy Environ. Sci., vol. 9, pp. 1476-1485, 2016.

[39] Z. Song, S. C. Watthage, A. B. Phillips, and M. J. Heben, "Pathways toward high-performance perovskite solar cells: Review of recent advances in organo-metal halide perovskites for photovoltaic applications," J. Photon. Energy, vol. 6, 2016, Art. no. 022001. 
[40] F. Hao, C. C. Stoumpos, D. H. Cao, R. P. H. Chang, and M. G. Kanatzidis, "Lead-free solid-state organic-inorganic halide perovskite solar cells," Nature Photon., vol. 8, pp. 489-494, 2014.

41] T. Krishnamoorthy et al.,"Lead-free germanium iodide perovskite materials for photovoltaic applications," J. Mater. Chem. A, vol. 3, pp. 2382923832, 2015.

[42] J. Burschka et al., "Sequential deposition as a route to high-performance perovskite-sensitized solar cells," Nature, vol. 499 pp. 316-319, 2013.

[43] M. A. Green, A. Ho-Baillie, and H. J. Snaith, "The emergence of perovskite solar cells," Nature Photon., vol. 8pp. 506-514, 2014.

[44] M. Gratzel, "The light and shade of perovskite solar cells," Nature Mater., vol. 13, pp. 838-842, 2014.

[45] B. Conings et al., "Intrinsic thermal instability of methylammonium lead trihalide perovskite," Adv. Energy Mater., vol. 5, 2015, Art. no. 1500477.

[46] C. C. Stoumpos, C. D. Malliakas, and M. G. Kanatzidis, "Semiconducting tin and lead iodide perovskites with organic cations: Phase transitions, high mobilities, and near-infrared photoluminescent properties,' Inorganic Chem., vol. 52, pp. 9019-9038, 2013.

[47] C. K. Moller, "Crystal structure and photoconductivity of caesium plumbohalides," Nature, vol. 182, pp. 1436-1436, 1958.

[48] N. J. Jeon et al., "Compositional engineering of perovskite materials for high-performance solar cells," Nature, vol. 517, pp. 476-480, 2015.

[49] J. P. Correa Baena et al., "Highly efficient planar perovskite solar cells through band alignment engineering," Energy Environ. Sci., vol. 8, pp. 2928-2934, 2015.

[50] H. Choi et al., "Cesium-doped methylammonium lead iodide perovskite light absorber for hybrid solar cells," Nano Energy, vol. 7, pp. 80-85, 2014.

[51] J.-W. Lee, D.-H. Kim, H.-S. Kim, S.-W. Seo, S. M. Cho, and N.-G. Park, "Formamidinium and cesium hybridization for photo- and moisture-stable perovskite solar cell," Adv. Energy Mater, vol. 5, 2015, Art. no. 1501310.

[52] X. Li et al., "A vacuum flash-assisted solution process for high-efficiency large-area perovskite solar cells," Science, vol. 353, pp. 58-62, 2016.

[53] Q. Chen et al., "Planar heterojunction perovskite solar cells via vaporassisted solution process," J. Amer. Chem. Soc., vol. 136, pp. 622-625, 2014.

[54] T. Leijtens, G. E. Eperon, N. K. Noel, S. N. Habisreutinger, A. Petrozza, and H. J. Snaith, "Stability of metal halide perovskite solar cells," Adv. Energy Mater., vol. 5, 2015.

[55] F. Matteocci et al., "Encapsulation for long-term stability enhancement of perovskite solar cells," Nano Energy, vol. 30, pp. 162-172, 2016.

[56] I. Mesquita, L. Andrade, and A. Mendes, "Perovskite solar cells: Materials, configurations and stability," Renewable Sustain. Energy Rev., vol. 82, pp. 2471-2489, 2017.

[57] Q. Tai et al., "Efficient and stable perovskite solar cells prepared in ambient air irrespective of the humidity," Nature Commun., vol. 7, 2016, Art. no. 11105.

[58] T. Leijtens, G. E. Eperon, S. Pathak, A. Abate, M. M. Lee, and H. J. Snaith, "Overcoming ultraviolet light instability of sensitized $\mathrm{TiO} 2$ with meso-superstructured organometal tri-halide perovskite solar cells," $\mathrm{Na}$ ture Commun., vol. 4, 2013, Art. no. 2885.

[59] Y. Han et al., "Degradation observations of encapsulated planar $\mathrm{CH} 3 \mathrm{NH} 3 \mathrm{PbI} 3$ perovskite solar cells at high temperatures and humidity," J. Mater. Chem. A, vol. 3, pp. 8139-8147, 2015.

[60] J. You et al., "Improved air stability of perovskite solar cells via solutionprocessed metal oxide transport layers," Nature Nanotechnol., vol. 11, pp. 75-81, 2016.

61] J. Gong, S. B. Darling, and F. You, "Perovskite photovoltaics: Life-cycle assessment of energy and environmental impacts," Energy Environ. Sci., vol. 8, pp. 1953-1968, 2015.

[62] E. Zimmermann et al., "Characterization of perovskite solar cells: Towards a reliable measurement protocol," APL Mater, vol. 4, 2016 , Art. no. 091901

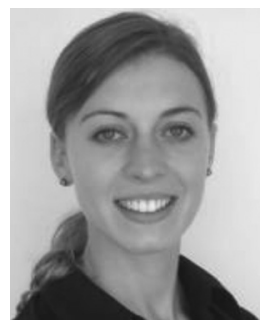

Verena Stockhausen received the B.S. degree in 730 chemistry and biochemistry and the M.S. degree 731 in chemistry from Ludwig Maximilians University, 732 Munich, Germany, in 2005 and 2007, respectively, 733 and the Ph.D. degree in analytical physical chem- 734 istry from Denis Diderot University, Paris, France, 735 in 2011.

In 2013 and from 2015 to 2017, she was a Post- 737 doc Fellow within the group of Prof. Adélio Mendes. 738 Her research interests include photovoltaic systems 739 such as dye-sensitized solar cells and perovskite so- 740 lar cells, as well as photoelectrochemical systems for water splitting.

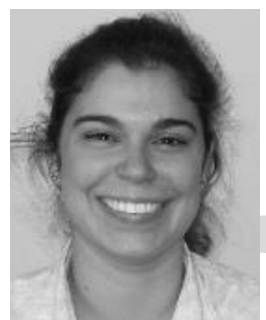

Isabel Mesquita was born in Porto, Portugal, in 1988. She received the M.S. degree in chemical engineer- 744 ing from the University of Porto, Porto, in 2011. She 745 is currently working toward the Ph.D. degree at the 746 Faculty of Engineering, University of Porto, focusing 747 in the perovskite solar cells and their stability. 748

From September of 2011 to March 2015, she 749 was a Research Fellow with LEPABE_Laboratory 750 for Process Engineering, Environment, Biotechnol- 751 ogy and Energy working in methanol fuel cells and 752 dye-sensitized solar cells. .

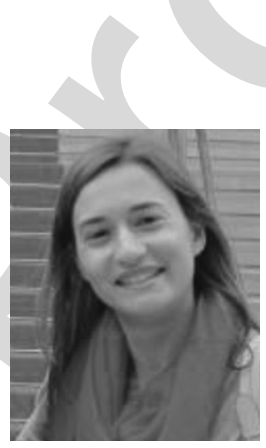
Luisa Andrade received the Ph.D. degree from the
University of Porto, Porto, Portugal, in 2010, with the thesis "Study and Characterization of Grätzel Solar Cells."

is currently an Assistant Researcher with LEP- 759 ABE, Faculty of Engineering, University of Porto, 760 working with dye-sensitized solar cells and per- 761 ovskite solar cells. She worked directly with Prof. 762 Grätzel at the Laboratory of Photonic and Interfaces, 763 Lausanne, Switzerland.

Dr. Andrade was the recipient of the ACP Diogo 765 Vasconcelos award in 2011, the Solvay\&Hovione Innovation Challenge award 766 in 2011 and 2012, and the Ramos Catarino award in 2012.

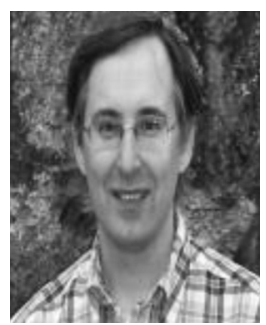

Adélio Mendes was born in 1964. He received the 769 Ph.D. degree from the University of Porto, Porto, Por- 770 tugal, in 1993.

He is a Full Professor with the Chemical Engineer- 772 ing Department, Faculty of Engineering, University 773 of Porto. He coordinates a large research team with re- 774 search interests mainly including dye-sensitized solar 775 cells and perovskite solar cells, photoelectrochemi- 776 cal cells, including water splitting and solar redox 777 flow cells, redox flow batteries, PEMFC, methanol 778 steam reforming, membrane, and adsorbent-based 779 gas separations. He received an Advanced Research Grant from the ERC on 780 dye-sensitized solar cells for building integrated of ca. 2 MEuros. He is cur- 781 rently the Coordinator of CEner-FEUP, the Competence Center for Energy of 782 the Faculty of Engineering at the University of Porto.

\section{.} 754

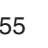
. 58 (1) 762 (t)

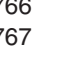

\section{.} 71 773 75 
- Authors: Please note that we cannot accept new source files as corrections for your paper. If possible, please annotate the PDF proof we have sent you with your corrections, using Adobe Acrobat editing software, and upload it via the Author Gateway. Alternatively, you may send us your corrections in a simple .txt file, utilizing the line numbers in the margins of the proof to indicate exactly where you would like for us to make corrections. You may, however, upload revised graphics via the Author Gateway.

\section{QUERIES}

Q1. Author: Please check whether the funding information is correct.

Q2. Author: Please provide the expansion of DMF, DMSO, and HTL.

Q3. Author: Please check the usage of the term "hydratation" in the sentence "Within the degradation mechanism of perovskite structures ...".

Q4. Author: Please provide missing year for Refs. [5] and [6].

Q5. Author: Please provide page rage for Ref. [54]. 